Review

\title{
Crk and CrkL as Therapeutic Targets for Cancer Treatment
}

\author{
Taeju Park $\mathbb{1}$
}

check for updates

Citation: Park, T. Crk and CrkL as Therapeutic Targets for

Cancer Treatment. Cells 2021, 10, 739.

https://doi.org/10.3390/cells10040739

Academic Editor: Antoni Wiedlocha

Received: 1 March 2021

Accepted: 24 March 2021

Published: 27 March 2021

Publisher's Note: MDPI stays neutral with regard to jurisdictional claims in published maps and institutional affiliations.

Copyright: (C) 2021 by the author. Licensee MDPI, Basel, Switzerland. This article is an open access article distributed under the terms and conditions of the Creative Commons Attribution (CC BY) license (https:/ / creativecommons.org/licenses/by/ $4.0 /)$.
Children's Mercy Research Institute, Children's Mercy Kansas City, Department of Pediatrics, University of Missouri Kansas City School of Medicine, Kansas City, MO 64108, USA; tjpark@cmh.edu

\begin{abstract}
Crk and CrkL are cellular counterparts of the viral oncoprotein v-Crk. Crk and CrkL are overexpressed in many types of human cancer, correlating with poor prognosis. Furthermore, gene knockdown and knockout of Crk and CrkL in tumor cell lines suppress tumor cell functions, including cell proliferation, transformation, migration, invasion, epithelial-mesenchymal transition, resistance to chemotherapy drugs, and in vivo tumor growth and metastasis. Conversely, overexpression of tumor cells with Crk or CrkL enhances tumor cell functions. Therefore, Crk and CrkL have been proposed as therapeutic targets for cancer treatment. However, it is unclear whether Crk and CrkL make distinct or overlapping contributions to tumor cell functions in various cancer types because Crk or CrkL have been examined independently in most studies. Two recent studies using colorectal cancer and glioblastoma cells clearly demonstrated that Crk and CrkL need to be ablated individually and combined to understand distinct and overlapping roles of the two proteins in cancer. A comprehensive understanding of individual and overlapping roles of Crk and CrkL in tumor cell functions is necessary to develop effective therapeutic strategies. This review systematically discusses crucial functions of Crk and CrkL in tumor cell functions and provides new perspectives on targeting Crk and CrkL in cancer therapy.
\end{abstract}

Keywords: Crk; CrkL; cancer; cell proliferation; transformation; migration; invasion; epithelialmesenchymal transition

\section{Introduction}

Oncogene $v$-crk was identified from chicken tumor virus number 10 (CT10) retrovirus and avian sarcoma virus [1,2]. The cellular counterparts of $v$-crk, CT10 regulator of kinase $(C R K)$ and CRK-like (CRKL), were discovered in humans on chromosome 17p13.3 and 22q11.21, respectively [3-5]. Crk and CrkL are adaptor proteins consisting of SH2 and SH3 domains. CrkII contains a single SH2 domain and two SH3 domains, and its splice variant CrkI lacks the c-terminal SH3 domain [5]. Although CrkI is known to be more effective at inducing cell transformation, it is less clear whether the two Crk splice variants differ in their expression and function. CrkL contains one SH2 and two SH3 domains and is similar to CrkII in structure and function [6]. Human CrkII and CrkL are 57\% identical, and mouse CrkII and CrkL are 56\% identical in amino acid comparison by the National Center for Biotechnology Information (NCBI) Protein BLAST. CrkII and CrkL are $99 \%$ and $97 \%$ identical, respectively, between human and mouse, suggesting that both proteins are highly conserved between the two species. Many proteins that bind to the SH2 and the N-terminal SH3 domains of Crk and CrkL have been identified. A few proteins are known to bind to the C-terminal SH3 domain. By mediating proteinprotein interactions through their $\mathrm{SH} 2$ and $\mathrm{SH} 3$ domains, Crk and CrkL play essential roles in signal transduction pathways [7]. Crk and CrkL are expressed ubiquitously, and they have been implicated in diverse biological processes (reviewed by Feller [6] and Birge et al. [8]). Crk and CrkL mediate cytoskeletal changes, cell proliferation, adhesion, migration, differentiation, phagocytosis, and pathogen uptake that are induced by growth factors, tyrosine kinase-coupled receptors, cytokines, integrins, mechanical force, and 
pathogens. Tyrosine phosphorylation of p130Cas, Cbl, Dab1, FAK, and paxillin play critical roles in these processes.

Due to structural and functional similarities between Crk and CrkL, overlapping roles of both proteins have been studied extensively in many biological processes. Crk and CrkL play essential overlapping roles in neuronal migration, neuromuscular synapse formation, podocyte morphogenesis, $\mathrm{T}$ cell migration into inflammation sites, natural killer cell expansion and differentiation during mouse cytomegalovirus infection, lens fiber cell elongation, and postnatal lens capsule development [9-15]. Furthermore, studies of Crk and CrkL in cultured fibroblasts have revealed that Crk and CrkL play essential overlapping roles in cell structure, motility, and growth [16-18]. All these discoveries were made possible by comparing phenotypes resulting from individual and combined knockout of Crk and CrkL in tissues and cells. On the other hand, severe developmental defects of both CRK-null and CRKL-null mouse embryos indicate that certain developmental processes require Crk or CrkL, or both $[19,20]$. CrkL has been reported to be essential in Fgf8induced survival and migration of cells during embryonic development [21]. Moreover, the heterozygous inactive mutation in CrkL in humans has been reported to cause congenital kidney anomalies of DiGeorge syndrome [22]. Recently, Imamoto et al. demonstrated that Crk, like CrkL, genetically interacts with Tbx1 and contributes to the organogenesis affected in DiGeorge syndrome [18]. Interestingly, loss of one allele from both CRK and $C R K L$ resulted in similar developmental phenotypes to those observed in the loss of two alleles from either $C R K$ or $C R K L$, suggesting shared functions by Crk and CrkL. In addition, both protection of $C R K$-null fibroblasts from irremediable endoplasmic reticulum (ER) stress and protection of $C R K$-null or $C R K L$-null kidney cells from toxic insults suggest that both Crk and CrkL mediate stress-induced cell death, with deficiency of one protein making a difference $[14,23,24]$.

Expression of Crk or CrkL is elevated in multiple human cancers, and the overexpression is positively correlated with poor prognosis. Reduced expression of either Crk or CrkL by RNA interference-mediated gene knockdown has been shown to lead to inhibition of in vivo tumor growth of various cancer cell lines. Unlike the systematic and comprehensive approaches made in the field of development, however, many of the early studies of Crk and CrkL in cancer have lacked thorough and quantitative comparisons among phenotypes that resulted from individual and combined gain or loss of Crk and CrkL (Table 1). Consequently, the existing data for Crk and CrkL provide valuable but limited insights into the contribution of Crk and CrkL to cancer cell function. This review systematically analyzes the studies on the role of Crk and CrkL in tumor cell functions to gain perspective on distinct and overlapping functions of Crk and CrkL in cancer cells. For each category of in vitro and in vivo phenotypes, relevant publications have been listed, starting with non-cancer cells and moving to cancer cells. Studies with gene knockdown or knockout are followed by studies with Crk and CrkL overexpression. Furthermore, perspectives on translating scientific knowledge into potential cancer therapy are provided. 
Table 1. Classification of cancers in which Crk and CrkL were studied for various tumor cell functions.

\begin{tabular}{|c|c|c|c|}
\hline Tumor Cell Function & Crk & CrkL & Crk and CrkL \\
\hline Cell spreading & Breast $[25,26]^{\mathrm{K}}$ & Glioblastoma [27] ${ }^{\mathrm{K}}$ & Glioblastoma [27] ${ }^{\mathrm{K}}$ \\
\hline In vitro cell proliferation & $\begin{array}{c}\text { Ovarian cancer }[28,29]^{\mathrm{K}} \\
\text { Synovial sarcoma }[30]^{\mathrm{K}} \\
\text { Hepatocellular }[31]^{\mathrm{O}}\end{array}$ & $\begin{array}{c}\text { Lung [32] }{ }^{\mathrm{O}} \\
\text { Rhabdomyosarcoma [33] }{ }^{\mathrm{K}} \\
\text { Breast [34] }{ }^{\mathrm{K}} \\
\text { Gastric [35] }{ }^{\mathrm{K}} \\
\text { Cervical [36] }{ }^{\mathrm{K}}[37]^{\mathrm{O}} \\
\text { Endometrial [38] } \\
\text { Hepatocellular [39] } \\
\text { Glioblastoma [27] }{ }^{\mathrm{K}}\end{array}$ & $\begin{array}{c}\text { Glioblastoma [27] }{ }^{\mathrm{K}} \\
\text { Colorectal [40] }\end{array}$ \\
\hline Anchorage-independent growth & $\begin{array}{c}\text { Ovarian [28] }{ }^{\mathrm{K}} \\
\text { Glioblastoma [41] }^{\mathrm{K}} \\
\text { Hepatocellular [31] }\end{array}$ & $\begin{array}{l}\text { Glioma [42] }{ }^{\mathrm{K}} \\
\text { Cervical [43] }\end{array}$ & $\begin{array}{c}\text { Breast [26] }{ }^{\mathrm{K}} \\
\text { Colorectal [40] } \\
\end{array}$ \\
\hline In vivo tumor growth & $\begin{array}{c}\text { Ovarian [28] }{ }^{\mathrm{K}} \\
\text { Glioblastoma [41] }{ }^{\mathrm{K}} \\
\text { Breast }[26,44]^{\mathrm{K}} \\
\text { Bladder }[45]^{\mathrm{K}}\end{array}$ & $\begin{array}{c}\text { Head and neck [46] }{ }^{\mathrm{K}} \\
\text { Rhabdomyosarcoma [33] } \\
\text { Hepatocellular [39] }\end{array}$ & \\
\hline Metastasis & $\begin{array}{c}\text { Breast [26] } \\
\text { Bladder [45] }^{\mathrm{K}}\end{array}$ & Colorectal [47] ${ }^{\mathrm{K}}$ & \\
\hline Migration and invasion & $\begin{array}{c}\text { Bladder [45] }{ }^{\mathrm{K},}[48]^{\mathrm{O}} \\
\text { Glioblastoma [27,41] }{ }^{\mathrm{K}}[49,50]^{\mathrm{O}} \\
\text { Fibrosarcoma [51] } \\
\text { Breast/cervical/lung [25] } \\
\text { Ovarian [28,29] } \mathrm{K} \\
\text { Synovial sarcoma [52] } \\
\text { Oral squamous [53] } \\
\text { Prostate [54,55] } \\
\text { K } \\
\text { Breast [26] }{ }^{\mathrm{K}},[56]^{\mathrm{O}} \\
\text { Lung [57,58] } \\
\text { Gastric [59] }{ }^{\mathrm{K}} \\
\text { Colorectal [40] } \\
\text { Kepatocellular [31] } \\
\text { Pancreatic [60] }\end{array}$ & $\begin{array}{l}\text { Head and neck [46] } \\
\text { Glioma [42] } \mathrm{K} \\
\text { Ovarian [61] }{ }^{\mathrm{K}} \\
\text { Hepatocellular [62] } \\
\text { Gastric [63] }{ }^{\mathrm{K}} \\
\text { Cervical [43] }{ }^{\mathrm{K}}[37]^{\mathrm{O}} \\
\text { Colorectal [40] }^{\mathrm{K}} \\
\text { Glioblastoma [27] }{ }^{\mathrm{K}}\end{array}$ & $\begin{array}{l}\text { Colorectal/pancreatic [40] } \\
\text { Glioblastoma }[27]^{\mathrm{K}}\end{array}$ \\
\hline $\begin{array}{l}\text { Epithelial-mesenchymal } \\
\text { transition }\end{array}$ & $\begin{array}{c}\text { Bladder [45] }{ }^{\mathrm{K}} \\
\text { Lung [64] }{ }^{\mathrm{O}} \\
\text { Breast [44] } \mathrm{K} \\
\text { Colorectal [40] } \\
\end{array}$ & $\begin{array}{c}\text { Ovarian [65] }]^{\mathrm{K}} \\
\text { Gastric [63] }{ }^{\mathrm{K}} \\
\text { Colorectal [40] }\end{array}$ & Colorectal/pancreatic [40] ${ }^{\mathrm{K}}$ \\
\hline Chemoresistance & & $\begin{array}{c}\text { Cervical [37] }{ }^{\mathrm{O}} \\
\text { Endometrial [38] }\end{array}$ & Colorectal [40] ${ }^{\mathrm{K}}$ \\
\hline $\begin{array}{l}\text { Overexpression } \\
\text { in cancer tissues }\end{array}$ & $\begin{array}{c}\text { Lung/gastric/breast [66] } \\
\text { Glioblastoma [41,50,56] } \\
\text { Lung [67] } \\
\text { Breast [25] } \\
\text { Oral squamous [53] } \\
\text { Bladder [45] } \\
\text { Gastric [68,69] } \\
\text { Kidney [56] }\end{array}$ & $\begin{array}{c}\text { Lung }[32,70] \\
\text { Rhabdomyosarcoma [33] } \\
\text { Breast [34] } \\
\text { Gastric [35,63] } \\
\text { Thyroid [71] } \\
\text { Ovarian [65] } \\
\text { Cervical [37,72] } \\
\text { Endometrial [38] } \\
\text { Pancreatic [73] } \\
\text { Colorectal [47] }\end{array}$ & $\begin{array}{c}\text { Ovarian [29] } \\
\text { Breast [26] }\end{array}$ \\
\hline Lower survival & $\begin{array}{c}\text { Oral squamous [53] } \\
\text { Glioblastoma [50] } \\
\text { Lung [64] } \\
\text { Gastric [68,69] } \\
\text { Colorectal [40] }\end{array}$ & $\begin{array}{c}\text { Lung [32] } \\
\text { Ovarian [65] } \\
\text { Gastric [63] } \\
\text { Pancreatic [73] } \\
\text { Colorectal [40] }\end{array}$ & Colorectal [40] \\
\hline
\end{tabular}

Studies in which Crk or CrkL was studied for the indicated tumor cell function are classified into cancer types and listed by year of publication of the earliest paper. References with the initial $\mathrm{K}$ indicate studies in which Crk or CrkL expression was decreased by gene knockdown or knockout. References in the initial O indicate studies in which Crk or CrkL was overexpressed. Despite an effort to be inclusive in choosing the references for citation, a few publications were excluded due to unclear results. 


\section{Regulation of the Cytoskeletal Network by Crk and CrkL}

Cytoskeletal elements such as microtubules, actin filaments, and intermediate filaments are crucial in determining cell shape and maintaining cell-cell and cell-matrix interactions. Studies of the role of Crk and CrkL in cytoskeletal network rearrangement have provided insights into alterations of the cytoskeleton in cancer cells. Stable overexpression of CrkI in rat $3 Y 1$ fibroblasts resulted in an alteration of cell morphology into refractile and spindle-like shapes [74]. Fibroblasts overexpressing CrkII were slightly spindle-shaped. The degree of the morphological alteration was proportional to the level of CrkI and correlated with colony formation in soft agar and in vivo tumor growth in nude mice. The results indicate that CrkI has a higher transforming capability than CrkII. On the other hand, overexpression of Madin-Darby canine kidney epithelial cells with CrkII or CrkL promoted lamellipodia formation and cell spreading with loss of adherens junctions and reduced $\beta$-catenin staining at cell-cell junctions [75]. Overexpression of T47D breast cancer epithelial cells with CrkII also caused dispersal of colonies [75]. CrkII overexpression in NIH3T3 cells made cells larger with enhanced lamellipodium formation [76]. In addition, overexpression of non-small cell lung cancer cells with CrkI or CrkII decreased expression of p120-catenin, a key member of adherens junction [77]. These studies demonstrate that overexpression of Crk family proteins results in reorganization of the actin cytoskeleton, weakened cell-cell junctions, and enhanced lamellipodia or spindle formation, thus leading to enhanced dispersal and spreading of cells.

On the other hand, gene knockdown studies have provided different insights into the functions of Crk and CrkL on the cell cytoskeleton. Crk knockdown in NIH3T3 cells resulted in a slower rate of cell spreading, more filopodia formation, and reduced focal adhesion formation in the early stages of cell spreading onto fibronectin-coated surfaces [76]. Furthermore, Crk/CrkL double knockdown, but not Crk or CrkL single knockdown, in NIH3T3 cells led to nearly complete inhibition of focal adhesion formation in the absence of PDGF [78]. The Crk/CrkL double knockdown also inhibited platelet-derived growth factor (PDGF)-induced circular dorsal membrane ruffle formation as well as focal adhesion disassembly. CrkII and CrkL preferentially activated the small GTPase Rac1, whereas CrkI preferentially activated Rap1 [78]. In addition, ablation of both Crk and CrkL from mouse embryonic fibroblasts resulted in a decrease in focal adhesion sites, reduced actin stress fibers, and a collapse of microtubule structures [16]. Fibroblasts lacking Crk or CrkL alone displayed a much more modest phenotype. In addition, breakdown of adherens junctions between neighboring fibroblasts was inhibited in immortalized mouse embryonic fibroblasts lacking both Crk and CrkL, leading to failure of cell dispersion and tight cell cluster formation [17]. These results suggest that Crk and CrkL have essential overlapping functions in maintaining the cytoskeletal network integrity and controlling cytoskeletal network rearrangement in fibroblasts.

The effect of Crk and CrkL on the cell cytoskeleton has also been demonstrated in cancer cell lines. Crk knockdown resulted in decreased spreading of a breast cancer cell line onto a fibronectin substrate with decreases in focal adhesions and actin stress fibers [25]. In addition, knockdown of both Crk and CrkL in the breast cancer cell line resulted in defective lamellipodia formation and delayed cell spreading on fibronectin [26]. In a glioblastoma cell line, both CrkL knockdown and Crk/CrkL double knockdown caused cells to shrink and become rounded. The morphological alterations, quantified by the cytoplasmic area and the roundness, were more significant with Crk/CrkL double knockdown than with CrkL knockdown [27]. Taken together, these studies demonstrate that Crk and CrkL play critical overlapping roles in the reorganization of the cytoskeletal network and are required for the spreading of fibroblasts and cancer cells.

\section{Regulation of In Vitro Cell Proliferation by Crk and CrkL}

Uncontrolled cell proliferation is a crucial feature of many tumor cell lines. Crk and CrkL have been studied for their roles in normal and cancer cell proliferation. A close comparison of the Crk- and CrkL-mediated effects between normal and cancer cells 
may provide valuable insights into therapeutics. Ablation of endogenous Crk and CrkL from immortalized fibroblasts using Cre-loxP recombination-mediated gene knockout caused a blockage of cell proliferation and arrest of the cell cycle at the G1-S transition [17]. While loss of either Crk or CrkL alone conferred a much more modest reduction in cell proliferation, reintroduction of CrkI, CrkII, or CrkL individually rescued cell proliferation in the absence of the endogenous Crk and CrkL, suggesting overlapping functions of $\mathrm{Crk}$ and CrkL in fibroblast proliferation.

While there are few reports about the effects of Crk and CrkL on cell proliferation in non-transformed cells, Crk and CrkL have been studied extensively for their effects in a number of cancer cell lines. In those studies, Crk and CrkL were ablated by gene knockdown or overexpressed to investigate their cellular functions. Reduction in CrkII and CrkI protein levels by Crk knockdown led to inhibition of cell proliferation in MCAS and SKOV3 ovarian cancer [28,29] and synovial sarcoma cell lines [30] (Table 1). CrkL knockdown also inhibited cell proliferation in rhabdomyosarcoma [33], MDA-MB-453 breast cancer [34], MKN-45 gastric cancer [35], hepatocellular carcinoma [39], and HeLa cell lines [36]. Loss of both Crk and CrkL by CRISPR/Cas9 caused inhibition of proliferation of colon cancer cells [40]. In addition, individual and combined knockdown of Crk and CrkL in U-118MG glioblastoma cells demonstrated that CrkL knockdown and Crk/CrkL double knockdown, but not Crk knockdown, inhibited cell proliferation [27].

On the other hand, CrkII overexpression promoted proliferation of Hca-P hepatocarcinoma cells [31]. CrkL overexpression also promoted cell proliferation in non-small cell lung cancer (NSCLC) [32], cervical carcinoma [37], and Ishikawa endometrial carcinoma [38] cell lines. Crk knockdown and CrkL knockdown induced arrest of the cell cycle at G1 in synovial sarcoma [30] and gastric cancer cells [35], respectively. In contrast, cell cycle progression was observed with CrkL overexpression in NSCLC [32] and Ishikawa endometrial carcinoma [38] cell lines.

Taken together, these studies demonstrate essential functions of Crk or CrkL in cell cycle progression and cell proliferation in a variety of cancer cell lines. Since many of these studies addressed either Crk or CrkL, but not both, it is less clear whether the effects on cell proliferation are unique to one protein or shared by both proteins in a given cancer type. Therefore, it is premature to conclude why some cancer cells depend on Crk and others depend on CrkL to proliferate. Systematic comparison among individual and combined knockdown in various cancer cell lines would provide in-depth insights into this question.

\section{Regulation of Cell Transformation by Crk and CrkL}

$\mathrm{v}$-Crk was discovered as an oncogenic fusion protein that lacks catalytic activity but contains the viral gag sequence followed by an SH2 and an SH3 domain [1]. v-Crk was later found to be similar to CrkI [3]. Overexpression of v-Crk induced increases of tyrosinephosphorylated proteins and its association with phosphotyrosine-containing proteins, leading to transformation of chicken embryonic fibroblasts $[1,79,80]$. Both SH2 and SH3 domains were required for the v-Crk-induced transformation [81].

Matsuda et al. [74] cloned human CRKI and CRKII and demonstrated that CrkI overexpression in rat $3 Y 1$ cells induced transforming activities such as spindle-like cell morphology, anchorage-independent cell growth, and in vivo tumor growth in nude mice. However, cells with CrkII expression did not exhibit significant transforming activities except for slight morphological changes. On the other hand, CrkII overexpression induced transformation in different cell types, including Rat-1 [82] and NIH3T3 [83] fibroblasts. CrkL overexpression also induced cell transformation in Rat-1 fibroblasts in a RAS-dependent manner [84] and immortalized human airway epithelial cells [85]. Zheng et al. [86] demonstrated that C3G and SOS1 are required for anchorage-independent growth of NIH3T3 cells upon CrkI overexpression. In addition, Dok1 and RasGAP are reported to mediate Abl inhibition-mediated enhancement of transformation of NIH3T3 cells upon CrkI overexpression [87]. Furthermore, oncogenic transformation induced by $v$-fos or $v$-ras infection was inhibited in mouse fibroblast cell lines lacking endogenous Crk or CrkL [88]. 
Contribution of Crk and CrkL to anchorage-independent growth was demonstrated in several cancer cell lines (Table 1). Crk knockdown in human ovarian cancer cells and glioblastoma cells inhibited colony formation on soft agar [28,41]. CrkL knockdown also inhibited colony formation of glioma and cervical cancer cell lines on soft agar [42,43]. Ablation of CrkII, CrkI, and CrkL altogether suppressed anchorage-independent growth of MDA-231 breast cancer cells [26]. On the other hand, CrkII overexpression increased colony formation on soft agar in murine hepatocarcinoma cells [31]. These studies together suggest that overexpression of Crk or CrkL induces transformation of fibroblasts and that both Crk and CrkL are required for transformation of tumor cells. Since the transforming activities of CrkII, CrkI, and CrkL were not compared in each cell type, it is less clear whether different cell types require different Crk proteins for transformation.

\section{Regulation of In Vivo Tumor Growth and Metastasis by Crk and CrkL}

In line with their contribution to in vitro cell proliferation and anchorage-independent cell growth, effects of Crk and CrkL on in vivo tumor growth have been studied using the gene knockdown or knockout approach (Table 1). Crk knockdown in ovarian cancer [28], glioblastoma [41], breast cancer [26,44], and bladder cancer [45] cells resulted in decreased tumor growth in nude mice. CrkL knockdown also inhibited in vivo tumor growth in head and neck squamous cell carcinoma [46], rhabdomyosarcoma [33], hepatocellular carcinoma [39], and colorectal cancer [47] cells.

In addition to suppressing tumor growth at the primary injection sites in nude mice, Crk or CrkL knockdown reduced metastatic tumor burden. Bone metastasis in vivo following intra-cardiac injection of basal breast cancer cells was reduced by Crk knockdown [26]. Crk knockdown reduced metastatic tumor burden in blood, liver, and lung together with reductions in tumor volume at the primary site and the number of circulating tumor cells following orthotopic injection of bladder cancer cells under the bladder muscle layer [45]. In addition, Franke et al. [47] reported that SASH1 deficiency in colon cancer cells increased in vivo tumor formation at the primary site and the number of metastatic lesions, the latter being blocked by CRISPR/Cas9-based CrkL deficiency. These results demonstrate that in vivo tumor growth, likewise in vitro tumor cell proliferation, depends on Crk and CrkL.

\section{Regulation of Cell Migration and Invasion by Crk and CrkL}

Park and Curran reported that neuronal progenitor cell-specific knockout of $C R K$ and $C R K L$ was induced in mice to demonstrate that Crk and CrkL play essential overlapping roles in Reelin-dependent neuronal migration in the developing brain [9]. In this study, mice lacking Crk or CrkL alone in neurons did not exhibit the failure in neuronal migration. This was the first in vivo study to demonstrate the essential overlapping roles of $\mathrm{Crk}$ and CrkL in cell migration. Functions of Crk and CrkL in cell motility have been further studied at the cellular level. Antoku and Mayer [78] reported that PDGF-induced motility of NIH3T3 cells was decreased with Crk knockdown or CrkL knockdown and completely blocked with Crk/CrkL double knockdown. Ablation of both Crk and CrkL in mouse embryonic fibroblasts resulted in a decrease in cell motility [16,17]. Mouse fibroblasts lacking CrkL exhibited a decrease in cell migration toward fibronectin but not toward high serum [89]). In addition, $T$ cells lacking both Crk and CrkL showed defects in in vitro cell migration to CCL21 and CXCL10, trans-endothelial migration, and in vivo cell migration to inflamed tissues [11]. In contrast, Crk knockdown enhanced endothelial cell migration under intermittent hypoxia [90]. Overexpression of CrkII promoted cell migration and invasion in COS-7 cells [91,92] and Crk-null fibroblasts [56]. Expression of CrkII with a mutated SH2 domain inhibited insulin-induced migration and invasion of COS-7 cells [91,92]. CrkL overexpression promoted spontaneous migration of Ba/F3 hematopoietic cells [93].

Effects on cancer cell migration and invasion are the most extensively studied function of Crk and CrkL (Table 1). Rodrigues et al. [25] reported that Crk knockdown led to inhibition of cell migration and invasion in breast cancer, cervical carcinoma, and non- 
small cell lung carcinoma. Furthermore, Crk knockdown inhibited hepatocyte growth factor (HGF)-induced migration of breast cancer cells. Since then, Crk knockdown has been demonstrated to result in decreases in cancer cell migration and invasion in ovarian cancer [28,29], synovial cell carcinoma [52], glioblastoma [41], oral squamous cell carcinoma [53], prostate cancer [54,55], breast cancer [26], gastric cancer [59], bladder cancer [45], and pancreatic ductal adenocarcinoma [60] cells. CrkL knockdown also inhibited cell motility in head and neck squamous cell carcinoma [46] and migration and invasion of cervical cancer cells [43]. Furthermore, CrkL knockdown led to inhibition of TGF- $\beta 1$-induced cell motility in glioma [42] and ovarian cancer [61] cells. CrkL knockdown also resulted in a decrease in CCL20-induced migration and invasion of gastric cancer cells [63]. However, it was not clear whether the other protein between Crk and CrkL play similar roles because all the studies investigated effects by either Crk knockdown or CrkL knockdown in the given cancer cell type.

Recently, Franke et al. [40] demonstrated that loss of Crk or CrkL alone using CRISPR/ Cas9 substantially inhibited migration and invasion of colorectal cancer cells, while loss of both Crk and CrkL completely blocked cell migration and invasion. Crk/CrkL double knockout also inhibited pancreatic cancer cell migration and invasion. To investigate distinct and overlapping functions of Crk and CrkL, individual and combined knockdown of Crk and CrkL were induced in U-118MG glioblastoma cells, and cell migration and invasion were analyzed in real-time. While CrkL knockdown reduced glioblastoma cell migration, Crk knockdown delayed the cell migration $[27,94]$. When knockdown of both Crk and CrkL was induced, cell migration was completely blocked, suggesting the unique and overlapping functions of Crk and CrkL in glioblastoma cells. On the other hand, CrkL knockdown, but not Crk knockdown, inhibited glioblastoma cell invasion, and Crk/CrkL double knockdown completely blocked cell invasion. These findings indicate that individual and combined ablation of Crk and CrkL are required to address their unique and overlapping functions in tumor cells. In addition, real-time monitoring of cell migration and invasion might be needed to fully understand the contributions of Crk and CrkL to cell migration and invasion [94].

The effect of Crk and CrkL on tumor cell migration and invasion has also been studied using overexpression of Crk or CrkL in tumor cells. Transfection of U87MG glioblastoma cells with CrkI, but not CrkII, increased cell migration and invasion [49]. CrkII overexpression led to increased migration of rat bladder carcinoma cells [48], increased motility of fibrosarcoma [51], increased migration and invasion of Hs683 glioblastoma [50], increased migration of breast adenocarcinoma [56], and increased migration and invasion of murine hepatocarcinoma [31] cells. In contrast, expression of the N-terminal SH3 domain of Crk reduced motility and invasion of NSCLC cells [57]. Whereas CrkL overexpression inhibited migration and invasion of murine hepatocarcinoma cells [62], CrkL overexpression promoted invasion of cervical carcinoma cells [37].

The roles of tyrosine and serine phosphorylation of CrkII in binding to its target proteins in relation to cell motility have also been studied. Noren et al. [95] reported that treatment of breast cancer cells with Ephrin-B2 Fc increased CrkII phosphorylation on Tyr221 in an Abl-dependent manner, leading to inhibition of cell motility and invasion. Both CrkII-Y221F expression and Crk knockdown blocked the Ephrin-B2 Fc-induced inhibition of cell migration. Stimulation of HeLa cells with HGF also induced phosphorylation of CrkII on Tyr221 in an Abl-dependent manner, which led to inhibition of HGF-induced cell migration and served as a negative feedback loop [96]. Abl-induced phosphorylation of CrkII on Tyr221 and subsequent intramolecular binding of the SH2 domain to the phosphorylated Tyr221 are known to disrupt the association of CrkII to its SH2 target proteins $[97,98]$. In addition, Kobashigawa et al. [99] demonstrated that the inter-SH3 linker binds to $\mathrm{SH} 3$ domains and regulates the association of the $\mathrm{N}$-terminal SH3 domain to its targets. Therefore, these two kinds of intramolecular binding within CrkII reduce its transforming ability compared to CrkI. 
Whereas overexpression with CrkII-Y239F, like wild-type CrkII, increased migration of Crk-null fibroblasts and Hs683 glioblastoma cells, CrkII-Y239F, unlike wild-type CrkII, failed to increase migration of 4 T1 breast cancer cells [56]. Phosphorylation of CrkII on Tyr251 that is located on the C-terminal SH3 domain promoted motility of Crk-null mouse fibroblasts towards epidermal growth factor (EGF) [100]. On the other hand, CrkII-Ser41Gly expression decreased motility of NSCLC cells while wild-type CrkII expression increased the cell motility, suggesting that phosphorylation of CrkII on serine 41 by PAK1 promotes cell motility and invasion [58]. Therefore, depending on cancer cell types, phosphorylation of CrkII on different residues appears to be induced in response to external stimuli to modulate cell motility.

All these results suggest that Crk and CrkL play critical roles in tumor cell migration and invasion in a variety of cancers. In most of these studies, loss of either Crk or CrkL resulted in decreases in tumor cell migration and invasion, suggesting that tumor cell migration and invasion are highly demanding cellular processes that require both Crk and CrkL to reorganize the cellular cytoskeletal network. In particular, both Crk and CrkL have been demonstrated to be important for tumor cell migration and invasion in colorectal cancer, glioblastoma, ovarian cancer, cervical cancer, gastric cancer, and hepatocellular carcinoma (Figure 1). Furthermore, recent studies indicate that cell migration and invasion depend on Crk and CrkL in a dose-dependent manner since the loss of both Crk and CrkL led to more severe defects than the loss of one protein. In addition, the complete blockage of cell migration and invasion in the absence of Crk and CrkL suggests that cancer cells depend entirely on Crk and CrkL for their motility. Taken together, these results demonstrate that cell motility is a genuine cellular function of Crk and CrkL.

\section{Tumor cell migration and invasion}

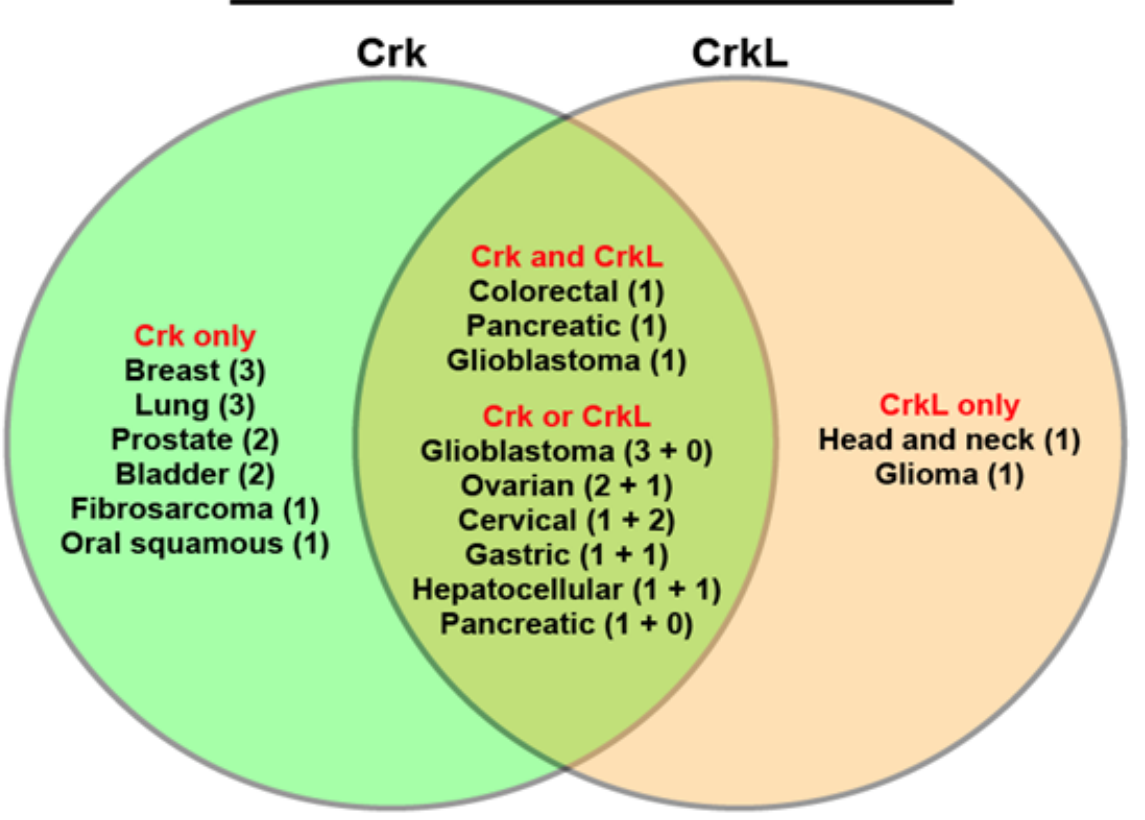

Figure 1. Diagram of cancers that are dependent on Crk and CrkL for tumor cell migration and invasion. The studies of Crk and CrkL in tumor cell migration and invasion were sorted by distinguishing whether Crk or CrkL or both were investigated in a given study. Then the studies were grouped into cancer types. The numbers inside the parentheses indicate the number of publications. The group "Crk and CrkL" includes the studies in which individual and combined alterations of Crk and CrkL expression were conducted at the same time, and the results were compared. The group "Crk or CrkL" includes the studies in which an individual alteration of Crk or CrkL expression was conducted in multiple publications. The two numbers for the group "Crk or CrkL" indicate the number of publications for Crk plus the number of publications for CrkL. For example, glioblastoma has 3 publications for Crk and 1 publication for both Crk and CrkL. 


\section{Regulation of EMT and Chemoresistance by Crk and CrkL}

The epithelial-mesenchymal transition (EMT) is a process by which epithelial cells lose their cell polarity and cell-cell adhesion, and gain mesenchymal cell properties such as spindle shape, increased survival, and migratory and invasive properties. At the molecular level, EMT is characterized by loss of epithelial markers, including E-cadherin, integrins, and cytokeratins, and gain of mesenchymal markers, including N-cadherin, vimentin, and fibronectin. The EMT switch is mediated through transcriptional reprogramming of crucial transcription factors such as Snail, Slug, TWIST1, ZEB1, and ZEB2 [101]. Knockdown of CrkI and CrkII significantly reduced the EMT in human bladder cancer cells by decreasing expression of N-cadherin, ZEB-1, vimentin, and fibronectin and increasing E-cadherin expression. This effect was accompanied by a reduction in HGF expression, c-Met activity, and Gab1 phosphorylation [45] (Table 1). Crk knockout using CRISPR/Cas9 decreased Ncadherin expression and increased expression of $\beta$-catenin and E-cadherin in murine breast adenocarcinoma cells, leading to loss of mesenchymal-like spindle-shaped cell morphology and increased cell-to-cell adhesion [44].

CrkL knockdown also suppressed CCL19/CCR7-induced EMT marker expression and extracellular signal-regulated kinase (ERK) phosphorylation in epithelial ovarian carcinoma cells by decreasing expression of N-cadherin, Snail, and MMP9 and increasing Ecadherin expression [65]. CrkL knockdown inhibited CCL20/CCR6-induced EMT marker expression and ERK phosphorylation in gastric cancer cells by decreasing expression of $\mathrm{N}$-cadherin, vimentin, and MMP2 [63]. While CrkL knockout blocked SASH1 deficiencyinduced EMT in HCT116 colon cancer cells [47], Crk/CrkL double knockout inhibited Src activation-induced EMT [40]. Increased E-cadherin expression and decreased ZEB1 expression were observed by knockout of Crk, CrkL, or both in colon cancer cells and by Crk/CrkL double in pancreatic cancer cells [40]. On the other hand, overexpression of A549 human lung carcinoma cells with CrkI or CrkII stimulated the EMT by increasing expression of Snail, Slug, N-cadherin, Fibronectin, and MMP2 and decreasing E-cadherin expression [64]. The EMT induction by CrkI or CrkII overexpression was accompanied by increased TGF-b1 expression and mediated by Rac1 and RhoA. These results suggest that cells require Crk and CrkL for EMT.

Two in vivo studies have suggested a link between EMT and chemoresistance. Zheng et al. [102] demonstrated that suppression of EMT in pancreatic ductal adenocarcinoma mouse models by genetic ablation of EMT-inducing transcription factors such as Snail or Twist enhanced expression of nucleoside transporters in tumors, leading to enhanced sensitivity to gemcitabine treatment and increased overall survival of mice. In addition, Fischer et al. [103] demonstrated that breast cancer cells with EMT contribute to recurrent lung metastasis after chemotherapy, and that inhibition of EMT by overexpressing miR-200 abrogated the chemoresistance to cyclophosphamide treatment, leading to reduced lung metastasis. Interestingly, CrkL overexpression led to increased chemoresistance to cisplatin treatment in cervical carcinoma [37] and endometrial carcinoma [38] cells. Recently, Franke et al. [40] demonstrated decreased chemoresistance and EMT inhibition by loss of both Crk and CrkL in colon cancer cells. These results suggest that Crk and CrkL play important roles in EMT and chemoresistance and may provide a therapeutic target to improve the efficacy of chemotherapy drugs.

\section{Overexpression of Crk and CrkL in Human Cancers and Lower Survival}

Since Nishihara et al. [66] reported overexpression of Crk in various cancer tissues, including lung, gastric, and breast cancer tissues, Crk has been reported to be overexpressed in glioblastoma [41,49,50,56], lung cancer [67], breast cancer [25], oral squamous cell carcinoma [53], bladder cancer [45], gastric cancer [68,69], and kidney cancer [56] tissues (Table 1). Elevation of CrkL protein level is also reported in non-small cell lung cancer (NSCLC) [32,70], rhabdomyosarcoma [33], breast cancer [34], gastric cancer [35,63], thyroid cancer [71], ovarian cancer [65], cervical cancer [37,72], endometrial cancer [38], pancreatic ductal adenocarcinoma [73], and colorectal cancer [47] tissues. Increased expression of both 
Crk and CrkL is reported in ovarian cancer [29] and breast cancer [26] tissues. In particular, both Crk and CrkL have been reported to be overexpressed in ovarian, breast, gastric, and lung cancer tissues (Figure 2).

\section{Overexpressed in cancer tissues}

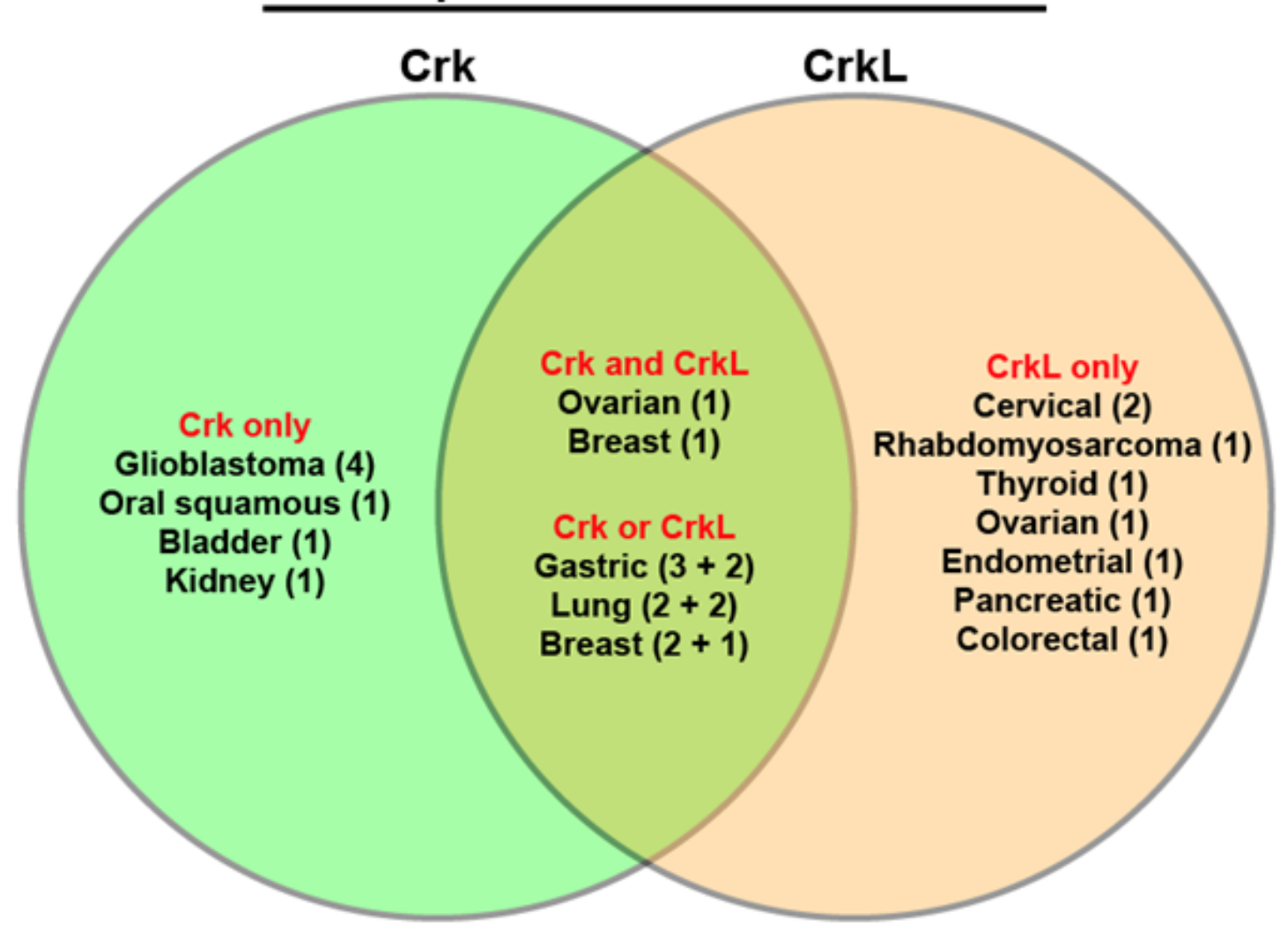

Figure 2. Diagram of cancers in which Crk and CrkL are overexpressed. The studies of Crk and CrkL protein expression in cancer tissues were sorted by distinguishing whether Crk or CrkL or both were investigated in a given study. Then the studies were grouped into cancer types. The numbers inside the parentheses indicate the number of publications. The group "Crk and CrkL" includes the studies in which overexpression of both Crk and CrkL was reported in a given study. The group "Crk or CrkL" includes the studies in which overexpression of Crk or CrkL expression was conducted in multiple publications. The two numbers for the group "Crk or CrkL" indicate the number of publications for Crk plus the number of publications for CrkL.

Higher expression of Crk in cancer tissues has been reported to contribute to poor prognosis and lower survival of patients with oral squamous cell carcinoma [53], glioblastoma [50], lung cancer [64], gastric cancer [68,69], and colorectal cancer [40]. Elevated expression of CrkL in cancer tissues also has been shown to lead to poor prognosis and lower survival of patients with NSCLC [32], ovarian cancer [65], gastric [63], pancreatic ductal adenocarcinoma [73], and colorectal cancer [40]. These results together suggest that Crk and CrkL are overexpressed in many cancer types and contribute to poor prognosis.

Since a majority of these studies conducted immunostaining to examine protein levels in tissues, it is unclear whether the elevated levels of Crk and CrkL proteins represent elevated levels of transcripts. Analysis of the curated set of non-redundant studies in The Cancer Genome Atlas (TCGA) using the cBioPortal platform [104,105] indicates that only $0.5 \%$ and $1 \%$ of cancer patients showed copy number increases for $C R K$ and $C R K L$, respectively. The results appear to be in a clear contrast to the results from the numerous studies of Crk and CrkL overexpression in cancer tissues (Table 1 and Figure 2). Although the lack of studies about a potential correlation between transcript and protein levels in various cancer types makes it difficult to draw any conclusion, it is possible that many cancers 
may modulate Crk and CrkL expression at the level of translation. It will be necessary to examine both copy number alterations and protein level changes in cancer tissue and study underlying mechanisms on how Crk and CrkL transcripts and proteins are upregulated in cancer. Nevertheless, lower survival was observed for the patients with amplification of CRK or CRKL transcripts (46.78 and 53.92 months for the median months overall, respectively, compared to 118.30 months with the unaltered group) (Figure 3 and Table 2). The results are consistent with the finding by Franke et al. [40]. The top 6 cancer types with 5 and higher cases of $C R K$ transcript amplification include ovarian cancer, endometrial cancer, prostate cancer, melanoma, breast cancer, and sarcoma. Both ovarian and breast cancer have been reported to have Crk overexpression (Figure 2) and to be dependent on Crk for tumor cell migration and invasion (Figure 1). The top 8 cancer types with 10 and higher cases of CRKL transcript amplification include lung cancer, melanoma, breast cancer, ovarian cancer, soft tissue sarcoma, bladder cancer, head and neck cancer, and sarcoma. While lung, breast, and ovarian cancer have been reported to have CrkL overexpression (Figure 2), ovarian and head and neck cancer have been reported to be dependent on CrkL for tumor cell migration and invasion (Figure 1). On the other hand, heterozygous or homozygous deletion of CRK or CRKL transcripts did not show any coherent results or clear trends (Table 2). Considering the well-established, overlapping functions of Crk and CrkL in a variety of signal transduction pathways, the effects of deletion can be less evident than those of amplification. Or the numbers of patients may yet be too small to display any meaningful correlation. A similar analysis using cBioPortal of a smaller subset for lung, breast, and gastric cancer patients combined did not exhibit any apparent difference in overall survival among the patients with amplification of $C R K$ and $C R K L$ transcripts (data not shown). Therefore, accumulation of more datasets, together with correlation studies between copy number alterations and protein level changes in cancer tissue, would provide a more concrete explanation of whether copy number alterations of $C R K$ and $C R K L$ contribute to overall patient survival in individual cancer types.

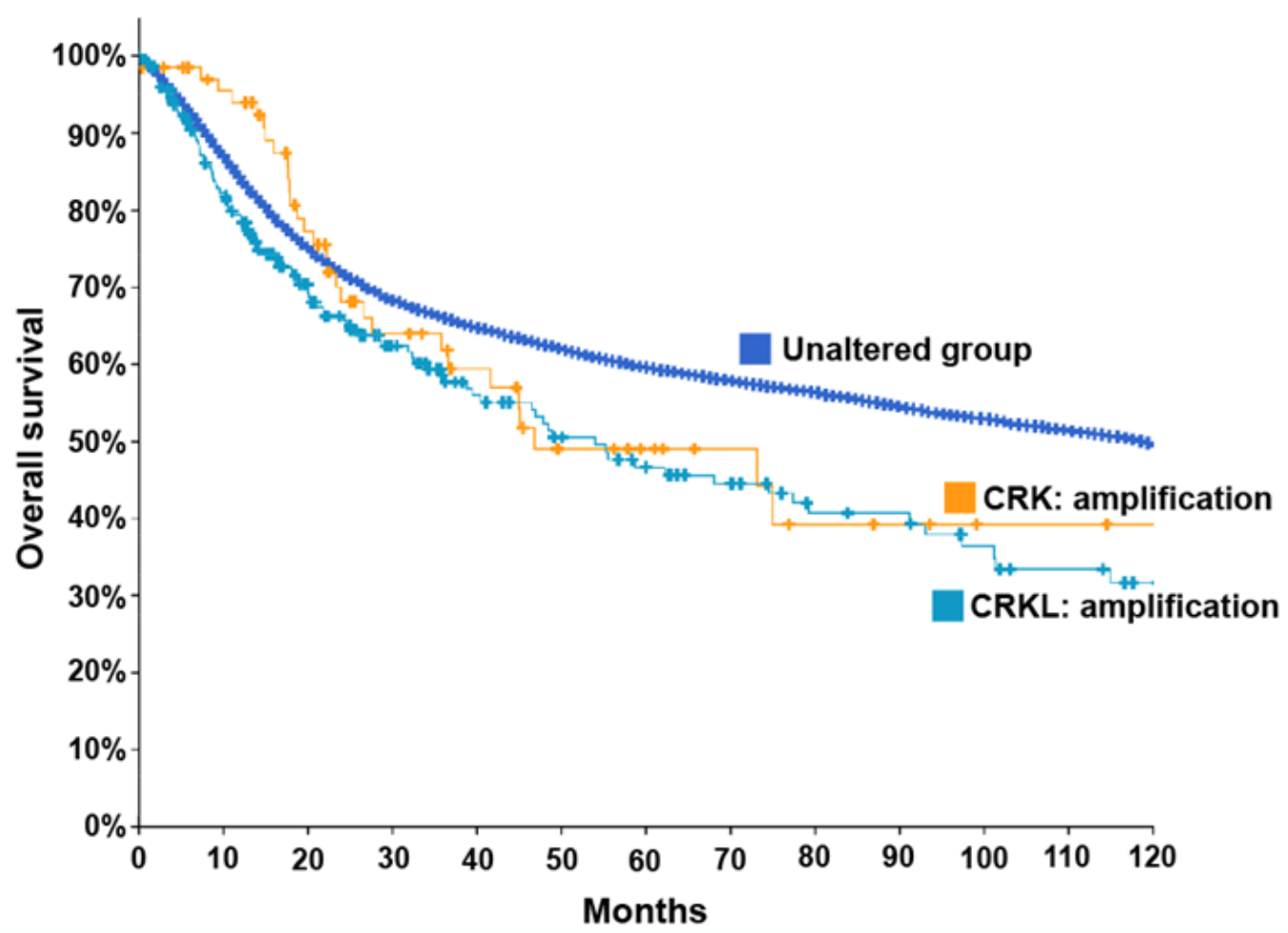

Figure 3. Decreased overall survival of patients with increased $C R K$ and $C R K L$ transcripts. The curated set of non-redundant studies in The Cancer Genome Atlas (TCGA) was analyzed by the cBioPortal $[104,105]$ for the correlation between copy number alterations and overall survival. The total number of cases and the median months overall for each group are presented in Table 2. 
Table 2. Overall survival of patients with gain or loss of Crk or CrkL transcripts.

\begin{tabular}{ccc}
\hline Copy Number Alteration & Total Number of Cases & Median Months Overall \\
\hline Unaltered group & 21,270 & 118.30 \\
CRK: amplification & 69 & 46.78 \\
CRKL: amplification & 231 & 53.92 \\
CRK: heterozygous deletion & 5072 & 81.93 \\
CRK: homozygous deletion & 108 & 94.00 \\
CRKL: heterozygous deletion & 3542 & 71.17 \\
CRKL: homozygous deletion & 51 & 158.00 \\
\hline
\end{tabular}

The curated set of non-redundant studies in The Cancer Genome Atlas (TCGA) was analyzed for copy number alterations by the cBioPortal [104,105]. The following Onco Query Language (OQL) queries were used in combinations to identify copy number alterations of Crk and CrkL: CRK: AMP, CrkL: AMP, CRK: HETLOSS, CRK: HOMDEL, CRKL: HETLOSS, and CRKL: HOMDEL. Depending on the OQL combination, the unaltered group ranged from 21,248 to 21,270 for the total number of cases and from 118.30 to 118.60 for the median months overall because of variations due to exclusion of overlapping samples and patients.

\section{Fibroblast Growth Factor Signaling and Tumor Cell Functions}

Crk and CrkL are known to mediate signal transduction pathways triggered by growth factors, including fibroblast growth factor (FGF) and other extracellular stimuli [6,8]. Stimulation of endothelial cells with FGF2 induced transient phosphorylation of Crk and complex formation between FGF receptor 1 (FGFR1) and Crk, leading to endothelial cell proliferation [106]. FGF2 also stimulated phosphorylation of Crk in heparan sulfate-deficient Chinese hamster ovary 677 cells expressing FGFR1 [107]. In addition, FGF8 and CrkL genetically interacted during cardiovascular, pharyngeal, and skeletal development [21]. Furthermore, CrkL bound to FGFR1 and FGFR2 upon FGF8 treatment, and CrkL was required for FGF8-induced fibroblast survival and migration [21].

Involvement of the FGF/FGFR receptor signaling pathways in tumor cell functions has been studied in a variety of tumor cell types. Treatment of breast cancer cells with FGF2 increased cell migration by inducing aquaporin 3 expression [108]. Treatment of breast cancer cells with FGF10 increased cell migration and invasion, colony formation, and EMT marker expression [109]. FGFR2 was highly expressed in many pancreatic ductal adenocarcinoma (PDAC) tissues, and knockdown of FGFR2 IIIb and IIIc in PDAC cells inhibited cell proliferation, migration, invasion, and in vivo tumor formation [110]. FGF8 was elevated in colorectal cancer tissues, and high FGF8 expression in colorectal cancer cells led to EMT marker expression, enhanced proliferation and invasion, and in vivo tumor growth and metastasis in a YAP1-dependent manner [111]. Fibroblasts induced contactand FGF2-dependent migration and invasion of colorectal cancer cells [112]. FGFR4 expression was elevated in nasopharyngeal carcinoma tissues, and FGFR4 knockdown reduced proliferation and migration of nasopharyngeal carcinoma cells [113]. Treatment of lung cancer cells with FGF4, but not FGF7, induced EMT, cell proliferation, migration, invasion, in vivo tumor formation, and metastasis by increasing store-operated calcium entry [114]. FGFR2 expression was elevated in gastric cancer tissues, and treatment of gastric cancer cells with FGF7 stimulated cell migration and invasion through thrombospondin upregulation [115]. FGF1 secreted from cancer-associate fibroblasts induced phosphorylation of FGFR4 and promoted ovarian cancer cell proliferation, migration, and invasion [116]. FGF8 expression is elevated in oral squamous cell carcinoma tissues, and treatment of oral squamous cell carcinoma cell lines with FGF8 promoted cell migration, invasion, and EMT [117].

These studies together demonstrate that FGF/FGFR signaling pathways promote migration and invasion of various tumor cells. Recent studies using mutant mouse models have demonstrated that Crk and CrkL play essential overlapping roles in FGF-induced lens fiber cell elongation during embryonic eye development [12] and postnatal lens development [15]. These studies clearly emphasize the importance of investigating potential contribution of Crk and CrkL to the FGF/FGF receptor (FGFR) signaling pathways. Given the roles of Crk and CrkL in various growth factor receptor-mediated signal transduction pathways, it will be important to study whether Crk and CrkL are required in the enhance- 
ment of tumor cell migration and invasion by the FGF/FGFR signaling pathways and other growth factor receptor-mediated pathways.

\section{Summary}

The contribution of Crk and CrkL to various tumor cell functions in vitro and in vivo has been studied extensively for the last two decades. A majority of the studies have focused on either Crk or CrkL and induced decreases or increases in protein levels in cells to study Crk and CrkL functions in vitro. The requirement of Crk or CrkL for cell proliferation in vitro, anchorage-independent cell growth, cell migration and invasion, in vivo tumor growth in mice, and metastasis has been demonstrated in multiple cancer cell lines. Overall, knockdown or knockout of Crk or CrkL suppressed tumor cell growth in vitro and in vivo, whereas overexpression of Crk or CrkL promoted tumor cell growth. Cancer cell migration and invasion were also inhibited by Crk or CrkL knockdown and promoted by Crk or CrkL overexpression. The effects of decreased levels of either protein on cancer cell migration and invasion contrast with the absence of effects from the loss of either protein on neuronal migration in the developing brain and $\mathrm{T}$ cell migration to inflamed tissues $[9,11]$. Interestingly, migration and invasion of glioblastoma and colorectal, pancreatic, ovarian, cervical, gastric, and liver cancer cells were dependent upon both Crk and CrkL (Table 1 and Figure 2). In addition, EMT and chemoresistance required Crk or CrkL in several cancer cells.

Immunohistochemical examination of Crk and CrkL expression in tissue specimens from cancer patients revealed that many cancers had elevated protein levels of Crk or CrkL. Ovarian, breast, gastric, and lung cancers exhibited elevated expression of both Crk and CrkL (Figure 2). Furthermore, elevated levels of Crk or CrkL proteins contributed to poor prognosis. Lung, gastric, and colorectal cancer patients showed increased protein levels for both Crk and CrkL and lower survival. The TCGA database analysis using cBioPortal also indicates that amplification of Crk or CrkL transcripts contributes to poor prognosis (Figure 3). Although these studies were instrumental in demonstrating the critical roles of Crk and CrkL in a variety of cancers, most examined either Crk or CrkL and failed to compare the roles of Crk and CrkL. Therefore, it is less clear whether Crk or CrkL alone is involved in tumor cell functions and whether both proteins play overlapping or distinct roles in each cancer type.

Fathers et al. [26] used the two breast cancer cell lines that stably expressed shRNAs for Crk and CrkL knockdown and reduced expression of CrkII, CrkI, and CrkL altogether. These cell lines exhibited significant reductions in cell migration, invasion, spreading, in vivo tumor growth, and metastasis. However, it is less clear whether knockdown of both Crk and CrkL is required for the inhibitory effects because individual knockdown of Crk or CrkL was not compared in parallel. No inhibitory effect on cell migration and less pronounced inhibitory effects on cell invasion by transient, individual knockdown of Crk and CrkL indirectly suggest potentially overlapping functions of Crk and CrkL. Recently, Franke et al. [40] induced individual and combined knockout of Crk and CrkL in colorectal cancer cells. Loss of either Crk or CrkL substantially inhibited cell migration and invasion, while loss of both completely blocked cell migration and invasion. The results indicate that both Crk and CrkL are required for colorectal cell migration and invasion. On the other hand, Park et al. [27] induced individual and combined knockdown of Crk and CrkL in a glioblastoma cell line and demonstrated a predominant role of CrkL and overlapping roles of Crk and CrkL in glioblastoma cell migration. These two recent studies elaborate on the need to study both proteins individually and combined at the same time. A clear understanding of the individual and combined functions of Crk and CrkL in each cancer type is critical to identifying the therapeutic target.

\section{Future Directions for Therapeutic Intervention}

All these studies of Crk and CrkL using cancer tissues and cancer cell lines propose $\mathrm{Crk}$ and $\mathrm{CrkL}$ as promising therapeutic targets for cancer treatment. Several reviews have 
previously discussed the critical roles of Crk and CrkL in cancer [8,118-122]. However, no apparent progress has been made in translating the information and knowledge into clinical advancement, mainly due to the absence of Crk and CrkL inhibitors. Although genetic manipulations such as gene knockout, knockdown, or overexpression helped uncover the contribution of Crk and CrkL to various tumor cell functions in vitro and in vivo, there is a significant challenge in using the genetic manipulations as therapy tools.

In addition to genetic modulation of protein levels, activities of Crk and CrkL proteins can be modulated by chemical compounds, peptides, or peptidomimetics. However, it is still unclear what represents the activity of Crk and CrkL. Since Crk and CrkL are adaptor proteins that mediate protein-protein interactions through their $\mathrm{SH} 2$ and $\mathrm{SH} 3$ domains, their interactions with target proteins may represent the activity. The challenge of this concept is that Crk and CrkL are known to interact with many proteins in various signal transduction pathways. Nevertheless, Posern et al. [123] has developed peptides that were derived from C3G and bound to SH3 domains of Crk and CrkL with high affinity and selectivity. The peptides inhibited the binding of Crk to DOCK180, to SoS, and to C3G in vitro. Kardinal et al. [124] further modified the peptide to develop cell-penetrating $\mathrm{SH} 3$ blocker peptides that disrupted Bcr-Abl-CrkL complexes and inhibited proliferation of primary blast cells from chronic myelogenous leukemia patients. These two studies demonstrate that peptide sequences derived from SH2- or SH3-binding proteins may be used to develop inhibitors of the binding between Crk/CrkL and their SH2 or SH3 binding partners.

More studies are needed to understand which target proteins are key binding partners in promoting tumor cell functions before assay systems are developed to test the proteinprotein interactions. Inhibitors that are specific to an interaction of Crk and CrkL with a binding partner will be critical to understanding how much a given protein-protein interaction contributes to the entire function of Crk and CrkL. In order to test inhibitors, it is necessary to establish measurable, specific cellular responses mediated by Crk and CrkL. In a recent study by Park et al. [27], commercially available siRNAs were compared to identify specific and potent suppressors of Crk and CrkL using a human glioblastoma cell line. Using these siRNAs, single and double knockdowns of Crk and CrkL were induced in a glioblastoma cell line to analyze the resulting cellular phenotypes quantitatively. This study indicates that cell migration is a specific, measurable cellular outcome that requires both Crk and CrkL, providing a foundation for screening Crk and CrkL inhibitors.

Crk and CrkL have been reported to play essential overlapping functions in development $[9,10,12,14]$ and immune cell activities [11,13]. In addition, Crk and CrkL are required in various signal transduction pathways to carry out normal cellular functions, including cytoskeletal reorganization, cell proliferation, adhesion, and migration, upon stimulation with growth factors, tyrosine kinase-coupled receptors, cytokines, and integrins. Therefore, it is necessary to carefully examine differential effects of Crk and CrkL inhibitors between tumor cells and normal cells to assess potential side effects by Crk/CrkL-targeted therapies. Since many human cancer types exhibit elevated expression of Crk and CrkL, the protein levels of Crk and CrkL in cells may be a critical deciding factor between normal and oncogenic functions of Crk and CrkL. Cancer cells are probably more prone to a reduction in protein levels or activities of Crk and CrkL. Furthermore, some oncogenic effects or signal transduction pathways may be triggered when the protein levels of Crk and CrkL exceed certain thresholds. If a certain protein-protein interaction is induced only when cells overexpress Crk and CrkL, it may be a cancer-specific event and serve as a good therapeutic target. In addition, more attention should be paid to how the synthesis and degradation of the proteins are regulated, especially in cancer cells. Considering that either Crk or CrkL has been studied in many cancer types, it is likely that cancers in different tissue types have different preferential dependences on Crk and CrkL. Therefore, developing various inhibitors, and stimulators as well, that are specific to Crk or CrkL or both will serve as essential tools in therapeutic cancer intervention and basic science research. 
Author Contributions: T.P. contributed to reviewing the literature, writing and editing the manuscript, conducting the cBioPortal analyses, and generating the tables and figures.All authors have read and agreed to the published version of the manuscript.

Funding: This work was supported by a Katharine B. Richardson grant and by an MCA Partners Advisory Board grant from Children's Mercy Hospital (CMH) and the University of Kansas Cancer Center (KUCC).

Institutional Review Board Statement: Not applicable.

Informed Consent Statement: Not applicable.

Data Availability Statement: The data supporting the findings of this study are contained in the article. The data that are described but not shown in the article will be shared upon request by the author.

Acknowledgments: The author thanks Giridhar Mudduluru for writing some parts of the initial draft of this manuscript. The author is grateful to Tom Curran for his critical reading of this review article. The author also thanks Neka Large and the Medical Writing Center at Children's Mercy Kansas City for editing the manuscript.

Conflicts of Interest: The author declares no competing interests.

$\begin{array}{ll}\text { Abbreviations } \\ \text { Crk } & \text { CT10 regulator of kinase } \\ \text { CrkL } & \text { Crk-like } \\ \text { GBM } & \text { Glioblastoma } \\ \text { EMT } & \text { Epithelial-mesenchymal transition } \\ \text { TCGA } & \text { The Cancer Genome Atlas } \\ \text { OQL } & \text { Onco Query Language } \\ \text { NSCLC } & \text { Non-small cell lung cancer } \\ \text { FGF } & \text { Fibroblast growth factor } \\ \text { FGFR } & \text { Fibroblast growth factor receptor }\end{array}$

\section{References}

1. Mayer, B.J.; Hamaguchi, M.; Hanafusa, H. A novel viral oncogene with structural similarity to phospholipase C. Nat. Cell Biol. 1988, 332, 272-275. [CrossRef] [PubMed]

2. Tsuchie, H.; Chang, C.H.; Yoshida, M.; Vogt, P.K. A newly isolated avian sarcoma virus, ASV-1, carries the crk oncogene. Oncogene 1989, 4, 1281-1284.

3. Reichman, C.T.; Mayer, B.J.; Keshav, S.; Hanafusa, H. The product of the cellular crk gene consists primarily of SH2 and SH3 regions. Cell Growth Differ. Mol. Boil. J. Am. Assoc. Cancer Res. 1992, 3, 451-460.

4. Hoeve, J.T.; Morris, C.; Heisterkamp, N.; Groffen, J. Isolation and chromosomal localization of CRKL, a human crk-like gene. Oncogene 1993, 8, 2469-2474.

5. Prosser, S.; Sorokina, E.; Pratt, P.; Sorokin, A. CrkIII: A novel and biologically distinct member of the Crk family of adaptor proteins. Oncogene 2003, 22, 4799-4806. [CrossRef]

6. Feller, S.M. Crk family adaptors-signalling complex formation and biological roles. Oncogene 2001, 20, 6348-6371. [CrossRef]

7. Birge, R.B.; Knudsen, B.S.; Besser, D.; Hanafusa, H. SH2 and SH3-containing adaptor proteins: Redundant or independent mediators of intracellular signal transduction. Genes Cells 1996, 1, 595-613. [CrossRef] [PubMed]

8. Birge, R.B.; Kalodimos, C.; Inagaki, F.; Tanaka, S. Crk and CrkL adaptor proteins: Networks for physiological and pathological signaling. Cell Commun. Signal. 2009, 7, 13. [CrossRef]

9. Park, T.-J.; Curran, T. Crk and Crk-Like Play Essential Overlapping Roles Downstream of Disabled-1 in the Reelin Pathway. J. Neurosci. 2008, 28, 13551-13562. [CrossRef] [PubMed]

10. Hallock, P.T.; Xu, C.-F.; Park, T.-J.; Neubert, T.A.; Curran, T.; Burden, S.J. Dok-7 regulates neuromuscular synapse formation by recruiting Crk and Crk-L. Genes Dev. 2010, 24, 2451-2461. [CrossRef]

11. Huang, Y.; Clarke, F.; Karimi, M.; Roy, N.H.; Williamson, E.K.; Okumura, M.; Mochizuki, K.; Chen, E.J.; Park, T.-J.; Debes, G.F.; et al. CRK proteins selectively regulate T cell migration into inflamed tissues. J. Clin. Investig. 2015, 125, 1019-1032. [CrossRef]

12. Collins, T.N.; Mao, Y.; Li, H.; Bouaziz, M.; Hong, A.; Feng, G.-S.; Wang, F.; Quilliam, L.A.; Chen, L.; Park, T.; et al. Crk proteins transduce FGF signaling to promote lens fiber cell elongation. eLife 2018, 7. [CrossRef] [PubMed]

13. Nabekura, T.; Chen, Z.; Schroeder, C.; Park, T.; Vivier, E.; Lanier, L.L.; Liu, N. Crk Adaptor Proteins Regulate NK Cell Expansion and Differentiation during Mouse Cytomegalovirus Infection. J. Immunol. 2018, 200, 3420-3428. [CrossRef] [PubMed] 
14. George, B.; Fan, Q.; Dlugos, C.P.; Soofi, A.A.; Zhang, J.; Verma, R.; Park, T.-J.; Wong, H.; Curran, T.; Nihalani, D.; et al. Crk1/2 and CrkL form a hetero-oligomer and functionally complement each other during podocyte morphogenesis. Kidney Int. 2014, 85, 1382-1394. [CrossRef] [PubMed]

15. Park, T.; Curran, T. Requirement for Crk and CrkL during postnatal lens development. Biochem. Biophys. Res. Commun. 2020, 529, 603-607. [CrossRef] [PubMed]

16. Park, T.-J.; Curran, T. Essential roles of Crk and CrkL in fibroblast structure and motility. Oncogene 2013, 33, 5121-5132. [CrossRef]

17. Park, T.; Koptyra, M.; Curran, T. Fibroblast Growth Requires CT10 Regulator of Kinase (Crk) and Crk-like (CrkL). J. Biol. Chem. 2016, 291, 26273-26290. [CrossRef]

18. Imamoto, A.; Ki, S.; Li, L.; Iwamoto, K.; Maruthamuthu, V.; Devany, J.; Lu, O.; Kanazawa, T.; Zhang, S.; Yamada, T.; et al. Essential role of the Crk family-dosage in DiGeorge-like anomaly and metabolic homeostasis. Life Sci. Alliance 2020, 3, e201900635. [CrossRef]

19. Guris, D.L.; A Fantes, J.; Tara, D.; Druker, B.J.; Imamoto, A. Mice lacking the homologue of the human 22q11.2 gene CRKL phenocopy neurocristopathies of DiGeorge syndrome. Nat. Genet. 2001, 27, 293-298. [CrossRef]

20. Park, T.-J.; Boyd, K.; Curran, T. Cardiovascular and Craniofacial Defects in Crk-Null Mice. Mol. Cell. Biol. 2006, 26, 6272-6282. [CrossRef]

21. Moon, A.M.; Guris, D.L.; Seo, J.-H.; Li, L.; Hammond, J.; Talbot, A.; Imamoto, A. Crkl Deficiency Disrupts Fgf8 Signaling in a Mouse Model of 22q11 Deletion Syndromes. Dev. Cell 2006, 10, 71-80. [CrossRef]

22. Lopez-Rivera, E.; Liu, Y.P.; Verbitsky, M.; Anderson, B.R.; Capone, V.P.; Otto, E.A.; Yan, Z.; Mitrotti, A.; Martino, J.; Steers, N.J.; et al. Genetic Drivers of Kidney Defects in the DiGeorge Syndrome. N. Engl. J. Med. 2017, 376, 742-754. [CrossRef] [PubMed]

23. Austgen, K.; Johnson, E.T.; Park, T.-J.; Curran, T.; Oakes, S.A. The adaptor protein CRK is a pro-apoptotic transducer of endoplasmic reticulum stress. Nat. Cell Biol. 2011, 14, 87-92. [CrossRef]

24. George, B.; Verma, R.; Soofi, A.A.; Garg, P.; Zhang, J.; Park, T.-J.; Giardino, L.; Ryzhova, L.; Johnstone, D.B.; Wong, H.; et al. Crk1/2-dependent signaling is necessary for podocyte foot process spreading in mouse models of glomerular disease. J. Clin. Investig. 2012, 122, 674-692. [CrossRef]

25. Rodrigues, S.P.; Fathers, K.E.; Chan, G.; Zuo, D.; Halwani, F.; Meterissian, S.; Park, M. CrkI and CrkII Function as Key Signaling Integrators for Migration and Invasion of Cancer Cells. Mol. Cancer Res. 2005, 3, 183-194. [CrossRef] [PubMed]

26. E Fathers, K.; Bell, E.S.; Rajadurai, C.V.; Cory, S.; Zhao, H.; Mourskaia, A.; Zuo, D.; Madore, J.; Monast, A.; Mes-Masson, A.-M.; et al. Crk adaptor proteins act as key signaling integrators for breast tumorigenesis. Breast Cancer Res. 2012, 14, R74. [CrossRef]

27. Park, T.; Large, N.; Curran, T. Quantitative assessment of glioblastoma phenotypes in vitro establishes cell migration as a robust readout of Crk and CrkL activity. J. Biol. Chem. 2021, 296, 100390. [CrossRef] [PubMed]

28. Linghu, H.; Tsuda, M.; Makino, Y.; Sakai, M.; Watanabe, T.; Ichihara, S.; Sawa, H.; Nagashima, K.; Mochizuki, N.; Tanaka, S. Involvement of adaptor protein Crk in malignant feature of human ovarian cancer cell line MCAS. Oncogene 2006, 25, 3547-3556. [CrossRef]

29. Wang, J.; Che, Y.-L.; Li, G.; Liu, B.; Shen, T.-M.; Wang, H.; Linghu, H. Crk and CrkL present with different expression and significance in epithelial ovarian carcinoma. Mol. Carcinog. 2011, 50, 506-515. [CrossRef]

30. Watanabe, T.; Tsuda, M.; Tanaka, S.; Ohba, Y.; Kawaguchi, H.; Majima, T.; Sawa, H.; Minami, A. Adaptor Protein Crk Induces Src-Dependent Activation of p38 MAPK in Regulation of Synovial Sarcoma Cell Proliferation. Mol. Cancer Res. 2009, 7, 1582-1592 [CrossRef]

31. Zhou, Z.; Sun, X.; Guo, C.; Sun, M.; Liu, S. CRKII overexpression promotes the in vitro proliferation, migration and invasion potential of murine hepatocarcinoma Hca-P cells. Oncol. Lett. 2019, 17, 5169-5174. [CrossRef] [PubMed]

32. Wang, Y.; Dong, Q.-Z.; Fu, L.; Stoecker, M.; Wang, E.; Wang, E.-H. Overexpression of crkl correlates with poor prognosis and cell proliferation in non-small cell lung cancer. Mol. Carcinog. 2012, 52, 890-899. [CrossRef]

33. Yeung, C.L.; Ngo, V.N.; Grohar, P.J.; I Arnaldez, F.; Asante, A.; Wan, X.; Khan, J.; Hewitt, S.M.; Khanna, C.; Staudt, L.M.; et al. Loss-of-function screen in rhabdomyosarcoma identifies CRKL-YES as a critical signal for tumor growth. Oncogene 2013, 32, 5429-5438. [CrossRef] [PubMed]

34. Zhao, T.; Miao, Z.; Wang, Z.; Xu, Y.; Wu, J.; Liu, X.; You, Y.; Li, J. Overexpression of CRKL correlates with malignant cell proliferation in breast cancer. Tumor Biol. 2013, 34, 2891-2897. [CrossRef] [PubMed]

35. Wang, J.; Chen, X.; Li, P.; Su, L.; Yu, B.; Cai, Q.; Li, J.; Yu, Y.; Liu, B.; Zhu, Z. CRKL promotes cell proliferation in gastric cancer and is negatively regulated by miR-126. Chem. Interact. 2013, 206, 230-238. [CrossRef]

36. Song, Q.; Yi, F.; Zhang, Y.; Li, D.K.J.; Wei, Y.; Yu, H.; Zhang, Y. CRKL regulates alternative splicing of cancer-related genes in cervical cancer samples and HeLa cell. BMC Cancer 2019, 19, 499. [CrossRef]

37. Ji, H.; Li, B.; Zhang, S.; He, Z.; Zhou, Y.; Ouyang, L. Crk-like adapter protein is overexpressed in cervical carcinoma, facilitates proliferation, invasion and chemoresistance, and regulates Src and Akt signaling. Oncol. Lett. 2016, 12, 3811-3817. [CrossRef]

38. Cai, L.; Wang, H.; Yang, Q. CRKL overexpression promotes cell proliferation and inhibits apoptosis in endometrial carcinoma. Oncol. Lett. 2017, 13, 51-56. [CrossRef]

39. Ren, Y.; Shang, J.; Li, J.; Liu, W.; Zhang, Z.; Yuan, J.; Yang, M. The long noncoding RNA PCAT-1 links the microRNA miR-215 to oncogene CRKL-mediated signaling in hepatocellular carcinoma. J. Biol. Chem. 2017, 292, 17939-17949. [CrossRef] [PubMed] 
40. Franke, F.C.; Slusarenko, B.O.; Engleitner, T.; Johannes, W.; Laschinger, M.; Rad, R.; Nitsche, U.; Janssen, K. Novel role for CRK adaptor proteins as essential components of SRC/FAK signaling for epithelial-mesenchymal transition and colorectal cancer aggressiveness. Int. J. Cancer 2020, 147, 1715-1731. [CrossRef]

41. Wang, L.; Tabu, K.; Kimura, T.; Tsuda, M.; Linghu, H.; Tanino, M.; Kaneko, S.; Nishihara, H.; Tanaka, S. Signaling adaptor protein Crk is indispensable for malignant feature of glioblastoma cell line KMG4. Biochem. Biophys. Res. Commun. 2007, 362, 976-981. [CrossRef] [PubMed]

42. Lv, S.; Qin, J.; Yi, R.; Coreman, M.; Shi, R.; Kang, H.; Yao, C. Crkl Efficiently Mediates Cell Proliferation, Migration, and Invasion Induced by TGF- $\beta$ Pathway in Glioblastoma. J. Mol. Neurosci. 2013, 51, 1046-1051. [CrossRef] [PubMed]

43. Wang, Y.; Dong, X.; Hu, B.; Wang, X.-J.; Wang, Q.; Wang, W.-L. The effects of Micro-429 on inhibition of cervical cancer cells through targeting ZEB1 and CRKL. Biomed. Pharmacother. 2016, 80, 311-321. [CrossRef]

44. Kumar, S.; Davra, V.; Obr, A.E.; Geng, K.; Wood, T.L.; De Lorenzo, M.S.; Birge, R.B. Crk adaptor protein promotes PD-L1 expression, EMT and immune evasion in a murine model of triple-negative breast cancer. Oncolmmunology 2017, 7, e1376155. [CrossRef] [PubMed]

45. Matsumoto, R.; Tsuda, M.; Wang, L.; Maishi, N.; Abe, T.; Kimura, T.; Tanino, M.; Nishihara, H.; Hida, K.; Ohba, Y.; et al. Adaptor protein CRK induces epithelial-mesenchymal transition and metastasis of bladder cancer cells through HGF /c-Met feedback loop. Cancer Sci. 2015, 106, 709-717. [CrossRef]

46. Yanagi, H.; Wang, L.; Nishihara, H.; Kimura, T.; Tanino, M.; Yanagi, T.; Fukuda, S.; Tanaka, S. CRKL plays a pivotal role in tumorigenesis of head and neck squamous cell carcinoma through the regulation of cell adhesion. Biochem. Biophys. Res. Commun. 2012, 418, 104-109. [CrossRef]

47. Franke, F.C.; Müller, J.; Abal, M.; Medina, E.D.; Nitsche, U.; Weidmann, H.; Chardonnet, S.; Ninio, E.; Janssen, K.-P. The Tumor Suppressor SASH1 Interacts With the Signal Adaptor CRKL to Inhibit Epithelial-Mesenchymal Transition and Metastasis in Colorectal Cancer. Cell. Mol. Gastroenterol. Hepatol. 2019, 7, 33-53. [CrossRef]

48. Petit, V.; Boyer, B.; Lentz, D.; Turner, C.E.; Thiery, J.P.; Vallés, A.M. Phosphorylation of Tyrosine Residues 31 and 118 on Paxillin Regulates Cell Migration through an Association with Crk in Nbt-II Cells. J. Cell Biol. 2000, 148, 957-970. [CrossRef] [PubMed]

49. Takino, T.; Nakada, M.; Miyamori, H.; Yamashita, J.; Yamada, K.M.; Sato, H. CrkI adapter protein modulates cell migration and invasion in glioblastoma. Cancer Res. 2003, 63, 2335-2337.

50. Kumar, S.; Lu, B.; Dixit, U.; Hossain, S.; Liu, Y.; Li, J.; Hornbeck, P.; Zheng, W.; Sowalsky, A.G.; Kotula, L.; et al. Reciprocal regulation of Abl kinase by Crk Y251 and Abi1 controls invasive phenotypes in glioblastoma. Oncotarget 2015, 6, 37792-37807. [CrossRef] [PubMed]

51. Takino, T.; Tamura, M.; Miyamori, H.; Araki, M.; Matsumoto, K.; Sato, H.; Yamada, K.M. Tyrosine phosphorylation of the CrkII adaptor protein modulates cell migration. J. Cell Sci. 2003, 116, 3145-3155. [CrossRef] [PubMed]

52. Watanabe, T.; Tsuda, M.; Makino, Y.; Ichihara, S.; Sawa, H.; Minami, A.; Mochizuki, N.; Nagashima, K.; Tanaka, S. Adaptor Molecule Crk Is Required for Sustained Phosphorylation of Grb2-Associated Binder 1 and Hepatocyte Growth Factor-Induced Cell Motility of Human Synovial Sarcoma Cell Lines. Mol. Cancer Res. 2006, 4, 499-510. [CrossRef]

53. Yamada, S.-I.; Yanamoto, S.; Kawasaki, G.; Rokutanda, S.; Yonezawa, H.; Kawakita, A.; Nemoto, T.K. Overexpression of CRKII increases migration and invasive potential in oral squamous cell carcinoma. Cancer Lett. 2011, 303, 84-91. [CrossRef] [PubMed]

54. Dai, Y.; Qi, L.; Zhang, X.; Li, Y.; Chen, M.; Zu, X. CrkI and p130Cas complex regulates the migration and invasion of prostate cancer cells. Cell Biochem. Funct. 2011, 29, 625-629. [CrossRef]

55. Dhupkar, P.; Zhao, H.; Mujoo, K.; An, Z.; Zhang, N. Crk II silencing down-regulates IGF-IR and inhibits migration and invasion of prostate cancer cells. Biochem. Biophys. Rep. 2016, 8, 382-388. [CrossRef] [PubMed]

56. Kumar, S.; Lu, B.; Davra, V.; Hornbeck, P.; Machida, K.; Birge, R.B. Crk Tyrosine Phosphorylation Regulates PDGF-BB-inducible Src Activation and Breast Tumorigenicity and Metastasis. Mol. Cancer Res. 2017, 16, 173-183. [CrossRef]

57. Pezeshkpour, G.H.; Moatamed, F.; Lewis, M.; Hoang, B.; Rettig, M.; Mortazavi, F. CRK SH3N Domain Diminishes Cell Invasiveness of Non-Small Cell Lung Cancer. Genes Cancer 2013, 4, 315-324. [CrossRef]

58. Rettig, M.; Trinidad, K.; Pezeshkpour, G.; Frost, P.; Sharma, S.; Moatamed, F.; Tamanoi, F.; Mortazavi, F. PAK1 Kinase Promotes Cell Motility and Invasiveness through CRK-II Serine Phosphorylation in Non-Small Cell Lung Cancer Cells. PLoS ONE 2012, 7, e42012. [CrossRef]

59. Li, X.; Wang, F.; Qi, Y. MiR-126 inhibits the invasion of gastric cancer cell in part by targeting Crk. Eur. Rev. Med Pharmacol. Sci. 2014, 18, 2031-2037.

60. Uemura, S.; Wang, L.; Tsuda, M.; Suzuka, J.; Tanikawa, S.; Sugino, H.; Nakamura, T.; Mitsuhashi, T.; Hirano, S.; Tanaka, S. Signaling adaptor protein Crk is involved in malignant feature of pancreatic cancer associated with phosphorylation of c-Met. Biochem. Biophys. Res. Commun. 2020, 524, 378-384. [CrossRef]

61. Cheng, S.; Guo, J.; Yang, Q.; Han, L. Crk-like adapter protein is required for TGF- $\beta$-induced AKT and ERK-signaling pathway in epithelial ovarian carcinomas. Tumor Biol. 2014, 36, 915-919. [CrossRef] [PubMed]

62. Lin, Q.; Sun, M.-Z.; Guo, C.; Shi, J.; Chen, X.; Liu, S. CRKL overexpression suppresses in vitro proliferation, invasion and migration of murine hepatocarcinoma Hca-P cells. Biomed. Pharmacother. 2015, 69, 11-17. [CrossRef]

63. Han, G.; Wu, D.; Yang, Y.; Li, Z.; Zhang, J.; Li, C. CrkL meditates CCL20/CCR6-induced EMT in gastric cancer. Cytokine 2015, 76, 163-169. [CrossRef] [PubMed] 
64. Elmansuri, A.Z.; Tanino, M.A.; Mahabir, R.; Wang, L.; Kimura, T.; Nishihara, H.; Kinoshita, I.; Dosaka-Akita, H.; Tsuda, M.; Tanaka, S. Novel signaling collaboration between TGF- $\beta$ and adaptor protein Crk facilitates EMT in human lung cancer. Oncotarget 2016, 7, 27094-27107. [CrossRef]

65. Cheng, S.; Guo, J.; Yang, Q.; Yang, X. Crk-like adapter protein regulates CCL19/CCR7-mediated epithelial-to-mesenchymal transition via ERK signaling pathway in epithelial ovarian carcinomas. Med Oncol. 2015, 32, 47. [CrossRef] [PubMed]

66. Nishihara, H.; Tanaka, S.; Tsuda, M.; Oikawa, S.; Maeda, M.; Shimizu, M.; Shinomiya, H.; Tanigami, A.; Sawa, H.; Nagashima, K. Molecular and immunohistochemical analysis of signaling adaptor protein Crk in human cancers. Cancer Lett. 2002, 180, 55-61. [CrossRef]

67. Miller, C.T.; Chen, G.; Gharib, T.G.; Wang, H.; Thomas, D.G.; E Misek, D.; Giordano, T.J.; Yee, J.; Orringer, M.B.; Hanash, S.M.; et al. Increased C-CRK proto-oncogene expression is associated with an aggressive phenotype in lung adenocarcinomas. Oncogene 2003, 22, 7950-7957. [CrossRef] [PubMed]

68. Yue, S.; Shi, H.; Han, J.; Zhang, T.; Zhu, W.; Zhang, D. Prognostic value of microRNA-126 and CRK expression in gastric cancer. OncoTargets Ther. 2016, 9, 6127-6135. [CrossRef] [PubMed]

69. Feng, R.; Sah, B.K.; Beeharry, M.K.; Yuan, F.; Su, L.; Jin, X.; Yan, M.; Liu, B.; Li, C.; Zhu, Z. Dysregulation of miR-126/Crk protein axis predicts poor prognosis in gastric cancer patients. Cancer Biomark. 2018, 21, 335-343. [CrossRef]

70. Itakura, M.; Terashima, Y.; Shingyoji, M.; Yokoi, S.; Ohira, M.; Kageyama, H.; Matui, Y.; Yoshida, Y.; Ashinuma, H.; Moriya, Y.; et al. High CC chemokine receptor 7 expression improves postoperative prognosis of lung adenocarcinoma patients. Br. J. Cancer 2013, 109, 1100-1108. [CrossRef] [PubMed]

71. Yang, X.; Lv, W.; Shi, R.; Cheng, S.; Zhang, J.; Xu, Z. The clinical implications of Crk-like adaptor protein expression in papillary thyroid microcarcinoma. Tumor Biol. 2014, 35, 12435-12440. [CrossRef]

72. Shi, X.; Xiao, X.; Yuan, N.; Zhang, S.; Yuan, F.; Wang, X. MicroRNA-379 Suppresses Cervical Cancer Cell Proliferation and Invasion by Directly Targeting V-crk Avian Sarcoma Virus CT10 Oncogene Homolog-Like (CRKL). Oncol. Res. Featur. Preclin. Clin. Cancer Ther. 2018, 26, 987-996. [CrossRef]

73. Wang, L.; Lu, J.; Wu, H.; Wang, L.; Liang, X.; Liang, Z.; Liu, T. Expression of signaling adaptor proteins predicts poor prognosis in pancreatic ductal adenocarcinoma. Diagn. Pathol. 2017, 12, 42. [CrossRef]

74. Matsuda, M.; Tanaka, S.; Nagata, S.; Kojima, A.; Kurata, T.; Shibuya, M. Two species of human CRK cDNA encode proteins with distinct biological activities. Mol. Cell. Biol. 1992, 12, 3482-3489. [CrossRef]

75. Lamorte, L.; Royal, I.; Naujokas, M.; Park, M. Crk Adapter Proteins Promote an Epithelial-Mesenchymal-like Transition and Are Required for HGF-mediated Cell Spreading and Breakdown of Epithelial Adherens Junctions. Mol. Biol. Cell 2002, 13, 1449-1461. [CrossRef]

76. Antoku, S.; Saksela, K.; Rivera, G.M.; Mayer, B.J. A crucial role in cell spreading for the interaction of Abl PxxP motifs with Crk and Nck adaptors. J. Cell Sci. 2008, 121, 3071-3082. [CrossRef]

77. Mortazavi, F.; Dubinett, S.; Rettig, M. c-Crk proto-oncogene contributes to transcriptional repression of p120-catenin in non-small cell lung cancer cells. Clin. Exp. Metastasis 2011, 28, 391-404. [CrossRef]

78. Antoku, S.; Mayer, B.J. Distinct roles for Crk adaptor isoforms in actin reorganization induced by extracellular signals. J. Cell Sci. 2009, 122, 4228-4238. [CrossRef]

79. Mayer, B.J.; Hanafusa, H. Association of the v-crk oncogene product with phosphotyrosine-containing proteins and protein kinase activity. Proc. Natl. Acad. Sci. USA 1990, 87, 2638-2642. [CrossRef]

80. Matsuda, M.; Mayer, B.J.; Hanafusa, H. Identification of domains of the v-crk oncogene product sufficient for association with phosphotyrosine-containing proteins. Mol. Cell. Biol. 1991, 11, 1607-1613. [CrossRef]

81. Matsuda, M.; Reichman, C.T.; Hanafusa, H. Biological and biochemical activity of v-Crk chimeras containing the SH2/SH3 regions of phosphatidylinositol-specific phospholipase C-gamma and Src. J. Virol. 1992, 66, 115-121. [CrossRef]

82. Senechal, K.; Heaney, C.; Druker, B.; Sawyers, C.L. Structural Requirements for Function of the Crkl Adapter Protein in Fibroblasts and Hematopoietic Cells. Mol. Cell. Biol. 1998, 18, 5082-5090. [CrossRef]

83. Iwahara, T.; Akagi, T.; Shishido, T.; Hanafusa, H. CrkII induces serum response factor activation and cellular transformation through its function in Rho activation. Oncogene 2003, 22, 5946-5957. [CrossRef]

84. Senechal, K.; Halpern, J.; Sawyers, C.L. The CRKL Adaptor Protein Transforms Fibroblasts and Functions in Transformation by the BCR-ABL Oncogene. J. Biol. Chem. 1996, 271, 23255-23261. [CrossRef]

85. Cheung, H.W.; Du, J.; Boehm, J.S.; He, F.; Weir, B.A.; Wang, X.; Butaney, M.; Sequist, L.V.; Luo, B.; Engelman, J.A.; et al. Amplification of CRKL Induces Transformation and Epidermal Growth Factor Receptor Inhibitor Resistance in Human NonSmall Cell Lung Cancers. Cancer Discov. 2011, 1, 608-625. [CrossRef]

86. Zheng, J.; Machida, K.; Antoku, S.; Ng, K.Y.; Claffey, K.P.; Mayer, B.J. Proteins that bind the Src homology 3 domain of CrkI have distinct roles in Crk transformation. Oncogene 2010, 29, 6378-6389. [CrossRef]

87. Ng, K.Y.; Yin, T.; Machida, K.; Wu, Y.I.; Mayer, B.J. Phosphorylation of Dok1 by Abl family kinases inhibits CrkI transforming activity. Oncogene 2015, 34, 2650-2659. [CrossRef]

88. Koptyra, M.; Park, T.-J.; Curran, T. Crk and CrkL are required for cell transformation by v-fos and v-ras. Mol. Carcinog. 2015, 55, 97-104. [CrossRef]

89. Li, L.; Guris, D.L.; Okura, M.; Imamoto, A. Translocation of CrkL to Focal Adhesions Mediates Integrin-Induced Migration Downstream of Src Family Kinases. Mol. Cell. Biol. 2003, 23, 2883-2892. [CrossRef] 
90. Toffoli, S.; Delaive, E.; Dieu, M.; Feron, O.; Raes, M.; Michiels, C. NDRG1 and CRK-I/II are regulators of endothelial cell migration under intermittent hypoxia. Angiogenesis 2009, 12, 339-354. [CrossRef]

91. Klemke, R.L.; Leng, J.; Molander, R.; Brooks, P.C.; Vuori, K.; Cheresh, D.A. CAS/Crk Coupling Serves as a "Molecular Switch" for Induction of Cell Migration. J. Cell Biol. 1998, 140, 961-972. [CrossRef]

92. Cho, S.Y.; Klemke, R.L. Extracellular-Regulated Kinase Activation and Cas/Crk Coupling Regulate Cell Migration and Suppress Apoptosis during Invasion of the Extracellular Matrix. J. Cell Biol. 2000, 149, 223-236. [CrossRef]

93. Uemura, N.; Griffin, J.D. The Adapter Protein Crkl Links Cbl to C3G after Integrin Ligation and Enhances Cell Migration. J. Biol. Chem. 1999, 274, 37525-37532. [CrossRef]

94. Mudduluru, G.; Large, N.; Park, T. Impedance-based Real-time Measurement of Cancer Cell Migration and Invasion. J. Vis. Exp. 2020, 158, e60997. [CrossRef] [PubMed]

95. Noren, N.K.; Foos, G.; Hauser, C.A.; Pasquale, E.B. The EphB4 receptor suppresses breast cancer cell tumorigenicity through an Abl-Crk pathway. Nat. Cell Biol. 2006, 8, 815-825. [CrossRef]

96. Cipres, A.; Abassi, Y.A.; Vuori, K. Abl functions as a negative regulator of Met-induced cell motility via phosphorylation of the adapter protein CrkII. Cell. Signal. 2007, 19, 1662-1670. [CrossRef] [PubMed]

97. Feller, S.; Knudsen, B.; Hanafusa, H. c-Abl kinase regulates the protein binding activity of c-Crk. EMBO J. 1994, 13, $2341-2351$. [CrossRef]

98. Rosen, M.K.; Yamazaki, T.; Gish, G.D.; Kay, C.M.; Pawson, T.; Kay, L.E. Direct demonstration of an intramolecular SH2Phosphotyrosine interaction in the Crk protein. Nat. Cell Biol. 1995, 374, 477-479. [CrossRef]

99. Kobashigawa, Y.; Sakai, M.; Naito, M.; Yokochi, M.; Kumeta, H.; Makino, Y.; Ogura, K.; Tanaka, S.; Inagaki, F. Structural basis for the transforming activity of human cancer-related signaling adaptor protein CRK. Nat. Struct. Mol. Biol. 2007, 14, 503-510. [CrossRef] [PubMed]

100. Sriram, G.; Jankowski, W.; Kasikara, C.; Reichman, C.; Saleh, T.; Nguyen, K.-Q.; Li, J.; Hornbeck, P.; Machida, K.; Liu, T.; et al. Iterative tyrosine phosphorylation controls non-canonical domain utilization in Crk. Oncogene 2014, 34, 4260-4269. [CrossRef]

101. Nieto, M.A.; Huang, R.Y.-J.; Jackson, R.A.; Thiery, J.P. EMT: 2016. Cell 2016, 166, 21-45. [CrossRef]

102. Zheng, X.; Carstens, J.L.; Kim, J.; Scheible, M.; Kaye, J.; Sugimoto, H.; Wu, C.-C.; LeBleu, V.S.; Kalluri, R. Epithelial-to-mesenchymal transition is dispensable for metastasis but induces chemoresistance in pancreatic cancer. Nat. Cell Biol. 2015, 527, 525-530. [CrossRef] [PubMed]

103. Fischer, K.R.; Durrans, A.; Lee, S.; Sheng, J.; Li, F.; Wong, S.T.C.; Choi, H.; El Rayes, T.; Ryu, S.; Troeger, J.; et al. Epithelialto-mesenchymal transition is not required for lung metastasis but contributes to chemoresistance. Nature 2015, 527, $472-476$. [CrossRef]

104. Cerami, E.; Gao, J.; Dogrusoz, U.; Gross, B.E.; Sumer, S.O.; Aksoy, B.A.; Jacobsen, A.; Byrne, C.J.; Heuer, M.L.; Larsson, E.; et al. The cBio Cancer Genomics Portal: An Open Platform for Exploring Multidimensional Cancer Genomics Data: Figure 1. Cancer Discov. 2012, 2, 401-404. [CrossRef] [PubMed]

105. Gao, J.; Aksoy, B.A.; Dogrusoz, U.; Dresdner, G.; Gross, B.; Sumer, S.O.; Sun, Y.; Jacobsen, A.; Sinha, R.; Larsson, E.; et al. Integrative Analysis of Complex Cancer Genomics and Clinical Profiles Using the cBioPortal. Sci. Signal. 2013, 6, pl1. [CrossRef]

106. Larsson, H.; Klint, P.; Landgren, E.; Claesson-Welsh, L. Fibroblast Growth Factor Receptor-1-mediated Endothelial Cell Proliferation Is Dependent on the Src Homology (SH) 2/SH3 Domain-containing Adaptor Protein Crk. J. Biol. Chem. 1999, 274, 25726-25734. [CrossRef]

107. Lundin, L.; Rönnstrand, L.; Cross, M.; Hellberg, C.; Lindahl, U.; Claesson-Welsh, L. Differential tyrosine phosphorylation of fibroblast growth factor (FGF) receptor-1 and receptor proximal signal transduction in response to FGF-2 and heparin. Exp. Cell Res. 2003, 287, 190-198. [CrossRef]

108. Cao, X.-C.; Zhang, W.-R.; Cao, W.-F.; Liu, B.-W.; Zhang, F.; Zhao, H.-M.; Meng, R.; Zhang, L.; Niu, R.-F.; Hao, X.-S.; et al. Aquaporin3 Is Required for FGF-2-Induced Migration of Human Breast Cancers. PLoS ONE 2013, 8, e56735. [CrossRef]

109. Abolhassani, A.; Riazi, G.H.; Azizi, E.; Amanpour, S.; Muhammadnejad, S.; Haddadi, M.; Zekri, A.; Shirkoohi, R. FGF10: Type III Epithelial Mesenchymal Transition and Invasion in Breast Cancer Cell Lines. J. Cancer 2014, 5, 537-547. [CrossRef]

110. Matsuda, Y.; Yoshimura, H.; Suzuki, T.; Uchida, E.; Naito, Z.; Ishiwata, T. Inhibition of fibroblast growth factor receptor 2 attenuates proliferation and invasion of pancreatic cancer. Cancer Sci. 2014, 105, 1212-1219. [CrossRef] [PubMed]

111. Liu, R.; Huang, S.; Lei, Y.; Zhang, T.; Wang, K.; Liu, B.; Nice, E.C.; Xiang, R.; Xie, K.; Li, J.; et al. FGF8 promotes colorectal cancer growth and metastasis by activating YAP1. Oncotarget 2014, 6, 935-952. [CrossRef]

112. Knuchel, S.; Anderle, P.; Werfelli, P.; Diamantis, E.; Rüegg, C. Fibroblast surface-associated FGF-2 promotes contact-dependent colorectal cancer cell migration and invasion through FGFR-SRC signaling and integrin $\alpha \mathrm{v} \beta 5$-mediated adhesion. Oncotarget 2015, 6, 14300-14317. [CrossRef]

113. Shi, S.; Li, X.; You, B.; Shan, Y.; Cao, X.; You, Y. High Expression of FGFR4 Enhances Tumor Growth and Metastasis in Nasopharyngeal Carcinoma. J. Cancer 2015, 6, 1245-1254. [CrossRef]

114. Qi, L.; Song, W.; Li, L.; Cao, L.; Yu, Y.; Song, C.; Wang, Y.; Zhang, F.; Li, Y.; Zhang, B.; et al. FGF4 induces epithelial-mesenchymal transition by inducing store-operated calcium entry in lung adenocarcinoma. Oncotarget 2016, 7, 74015-74030. [CrossRef]

115. Huang, T.; Wang, L.; Liu, D.; Li, P.; Xiong, H.; Zhuang, L.; Sun, L.; Yuan, X.; Qiu, H. FGF7/FGFR2 signal promotes invasion and migration in human gastric cancer through upregulation of thrombospondin-1. Int. J. Oncol. 2017, 50, 1501-1512. [CrossRef] [PubMed] 
116. Sun, Y.; Fan, X.; Zhang, Q.; Shi, X.; Xu, G.; Zou, C. Cancer-associated fibroblasts secrete FGF-1 to promote ovarian proliferation, migration, and invasion through the activation of FGF-1/FGFR4 signaling. Tumor Biol. 2017, 39, 1010428317712592. [CrossRef] [PubMed]

117. Hao, Y.; Xiao, Y.; Liao, X.; Tang, S.; Xie, X.; Liu, R.; Chen, Q. FGF8 induces epithelial-mesenchymal transition and promotes metastasis in oral squamous cell carcinoma. Int. J. Oral Sci. 2021, 13, 1-8. [CrossRef] [PubMed]

118. Sriram, G.; Birge, R.B. Emerging Roles for Crk in Human Cancer. Genes Cancer 2010, 1, 1132-1139. [CrossRef] [PubMed]

119. Bell, E.S.; Park, M. Models of Crk Adaptor Proteins in Cancer. Genes Cancer 2012, 3, 341-352. [CrossRef]

120. Tsuda, M.; Tanaka, S. Roles for Crk in Cancer Metastasis and Invasion. Genes Cancer 2012, 3, 334-340. [CrossRef]

121. Guo, C.; Liu, S.; Sun, M.-Z. The role of CT10 regulation of kinase-like in cancer. Futur. Oncol. 2014, 10, 2687-2697. [CrossRef] [PubMed]

122. Kumar, S.; Fajardo, J.E.; Birge, R.B.; Sriram, G. Crk at the Quarter Century Mark: Perspectives in Signaling and Cancer. J. Cell. Biochem. 2014, 115, 819-825. [CrossRef] [PubMed]

123. Posern, G.; Zheng, J.; Knudsen, B.S.; Kardinal, C.; Müller, K.B.; Voss, J.; Shishido, T.; Cowburn, D.; Cheng, G.; Wang, B.; et al. Development of highly selective SH3 binding peptides for Crk and CRKL which disrupt Crk-complexes with DOCK180, SoS and C3G. Oncogene 1998, 16, 1903-1912. [CrossRef] [PubMed]

124. Kardinal, C. Cell-penetrating SH3 domain blocker peptides inhibit proliferation of primary blast cells from CML patients. FASEB J. 2000, 14, 1529-1538. [CrossRef] 